\title{
CURRENT ENVIRONMENTAL REGULATION OF THE ALBERTA OIL AND GAS INDUSTRY AND EMERGING ISSUES
}

\author{
ALBERT J. HUDEC \& JONI R. PAULUS*
}

\begin{abstract}
As the environmental law regime in Alberta becomes increasingly detailed and stringent, participants in the oil and gas industry will face greater liability arising from environmental damage. This paper reviews the current provincial environmental regulatory structure as it applies to the oil and gas industry. Prospective developments in the law are also considered. The drafting of operating agreements, sale of oil and gas assets, and the liability of subsequent users are discussed in this context. Insurance coverage for environmental damage and the liability of lenders are also examined.
\end{abstract}

\section{INTRODUCTION}

This paper reviews the current and emerging environmental law regime applicable to the Alberta oil and gas industry. ${ }^{1}$ In particular, the paper discusses how the Energy Resources Conservation Board's (the "ERCB") regulation of oil and gas environmental issues meshes with the administration of Alberta's "umbrella" environmental statutes, the relationship between federal and provincial environmental regulation of the Alberta oil and gas industry and, finally, the current enforcement philosophy underlying the administration of Alberta's environmental laws and likely energy trends.

Draftsmen of commercial oil and gas agreements such as operating agreements are becoming sensitive to environmental issues as legislation becomes more complex and enforcement and penalties become more onerous. There are a number of means available to participants in the oil and gas industry to limit liabilities arising from environmental damage. This paper discusses some of these in light of emerging legislative trends.

\section{A. THE EXISTING REGULATORY REGIME}

The environmental aspects of oil and gas industry operations in Alberta are regulated by provincial environmental statutes of general application by statutory provisions specific to the oil and gas industry, by federal environmental statutes applicable in specific situations and by various published governmental and industry guidelines.

Alberta's major environmental statutes relevant to the oil and gas industry, which are administered by Alberta Environment include the Clean Air Act ${ }^{2}$ which regulates ambient air quality and air pollution; the Clean Water Act ${ }^{3}$ which regulates surface water and ground water pollution; and the Land Surface Conservation and

* Respectively, a Partner and an Associate at Blake, Cassels \& Graydon (formerly Duncan Collins), Barristers \& Solicitors, Calgary, Alberta. The authors would like to acknowledge the assistance of Bentley M. Woudstra, an associate at Blake, Cassels \& Graydon, in the preparation of this paper.

1. For a collection of U.S. papers on the same topic, see the Rocky Mountain Mineral Law Foundation, Environmental Consideration in National Resource and Real Property Transactions, Mineral Law Series, Volume 1988, Number 4; In Canada, see The Canadian Institute, Avoiding Environmental Liability in Real Estate \& Business Transactions, March, 1989.

2. R.S.A. 1980 , c. C-12.

3. R.S.A. 1980 , c. C-13. 
Reclamation Act, ${ }^{4}$ which regulates the restoration of lands disturbed by surface operations. The licensing and permitting provisions of the Clean Air Act and the Clean Water Act are, for example, specifically applicable to sour gas plants. Other oil and gas facilities which meet the criteria set out in ERCB Information Letter $86-2^{5}$ are exempt from the licensing and permitting requirements of these statutes.

Similarly, approval of reclamation plans prior to the commencement of operations under the Land Surface Conservation and Reclamation Act is required only in the case of regulated surface operations, namely oil and gas pipelines in excess of $150 \mathrm{~mm}$ in diameter and $16 \mathrm{~km}$ in length and oil sands operations. For other industry operations, reclamation certificates are required only at the time of site abandonment and reclamation must comply with guidelines established by the Land Surface Reclamation Counsel pursuant to section 36 of the Land Surface Conservations and Reclamation Act and a published letter to industry operators.

In addition, the environmental aspects of various industry operations are regulated under a number of industry-specific statutes administered primarily by the ERCB. For example, environmental issues relating to seismic activity are regulated pursuant to the Exploration Regulation ${ }^{6}$ under the Mines and Minerals Act ${ }^{7}$ wells, production facilities and gas plants are regulated pursuant to the Oil and Gas Conservation Regulations ${ }^{8}$ under the Oil and Gas Conservation Act ${ }^{9}$ pipeline construction and operations are regulated pursuant to the Pipeline Regulations ${ }^{10}$ under the Pipeline Act,$"$ and in situ oil sands operations are regulated under the Oil Sands Conservation Act. ${ }^{12}$

A number of other provincial statutes are relevant in specific situations. The Water Resources Act $t^{13}$ and the Ground Water Development Act ${ }^{14}$ are relevant to water usage in waterflood projects. Water Resources Permits under the Water Resources Act are required for long-term water uses such as in plants or steam injection wells. Letters of Authority are issued by Alberta Environment permitting the holder to direct and use water required for temporary uses such as hydro-

4. R.S.A. 1980 , c. L-3.

5. The ERCB publishes a package of information letters, bulletins, guidelines and policies, which are available from the ERCB at no charge.

The ERCB has published numerous regulations, information letters, interim directives and intemal policies dealing with specific environmental concerns. For example, the new guidelines for sulphur recovery issued on August 24, 1988, incorporate more stringent requirements for new plants and existing plants for which amendment applications are made.

Another example is the new noise guidelines issued pursuant to Interim Directive 88-1 on October 17, 1988 and intended to introduce a degree of site and project specificity to the noise standards applying to oil and gas industry activities.

6. Alta. Reg. $423 / 78$.

7. R.S.A. 1980 , c. M-15.

8. Alta. Reg. 151-71.

9. R.S.A. 1980 , c. 0-5.

10. Alta. Reg. 122-87.

11. R.S.A. 1980, c. P.8.

12. S.A. 1983 , c. $0-5.5$.

13. R.S.A. 1980 , c. W-5.

14. R.S.A. 1980 , c. G-11.1. 
static testing or as a drilling fluid. The Forest and Prairie Protection $A c t^{15}$ and Regulations ${ }^{16}$ and the Timber Management Regulations ${ }^{17}$ under the Forests $A c t^{18}$ are applicable when a person clears land for an industrial use.

Finally, the industry is self-regulated pursuant to various governmental and industry guidelines such as The Resource Handbook: Operational Guidelines for Industry prepared by the Forestry Land Use Branch of Alberta Energy and the Environmental Operating Guidelines for the Alberta Petroleum Industry published by the Canadian Petroleum Association.

\section{B. THE EXISTING REGULATORY PHILOSOPHY}

Alberta's existing laws governing environmental issues originated in the early 1970's and reflect a consultative approach. Although Alberta's standards for environmental protection are among the strictest in North America and Alberta's licensing and permit system is the most comprehensive in Canada, administrative mechanisms are the main tools to achieve abatement and compliance. Prosecution has only an indirect influence on abatement.

Currently, Alberta Environment's enforcement policy, as set out in a written summary entitled Approach to Pollution Control's Environmental Enforcement Program, relies primarily on administrative directives embodying negotiated compliance requirements based on technical discussions. For example, emission limits in licenses are frequently set unrealistically low and to some degree regarded as performance objectives rather than as realistically attainable standards which are expected to be strictly enforced. Directives, which were originally intended within the statutory regime as a means of obtaining information, frequently embody the terms of negotiated compliance standards. Control orders are not used on a regular and consistent basis. For example, there is minimal power under the existing statute to issue control orders against unregulated or unlicensed sources of emissions and there is no general offense provision under the Clean Air Act. Stop orders are rarely used, partly because the authority to issue stop orders is reserved to the Minister of the Environment.

Generally, the existing environmental regulatory regime has involved extensive industry/government consultation, both at the policy making and the policy enforcement stages. For example, government, oil and gas industry associations and individual members participate in a number of oil industry-specific environmental groups including, for example, the Prairie Regional Oil Spill Containments and Recovery Advisory Committee, the Petroleum Industry Training Service (training for oil and salt spill reclamation), the Reclamation Research Technical Advisory Committee (sponsored by Alberta Environment to consider reclamation research), the Environmental Research Advisory Council, the Alberta Petroleum Industry Government Environmental Committee, the Alberta Hazardous Chemicals Advisory Committee and the Saskatchewan/Alberta Waste Disposal Co-op Steering Committee. In the throne speech of February 17, 1989 the provincial government proposed the establishment of an Environmental Round Table consisting

15. R.S.A. 1980, c. F-14.

16. Alta. Reg. $135 / 72$ and Alta. Reg. $310 / 72$.

17. Alta. Reg. 60/73.

18. R.S.A. 1980 , c. F-16. 
of representatives of government, industry and public interest groups to discuss emerging policy issues in environmental law.

The evolution of specific policies within the ERCB through the use of specific decisions, interim directives and information letters currently involves extensive interaction with the industry. Industry has the opportunity, dealing with the ERCB which has sound technical expertise in oil and gas matters, to have significant input. This has resulted in a policy that emphasizes scientific, technical and economic considerations and the use of administrative mechanisms as the main tools to achieve abatement and compliance.

In addition to this technical and administrative emphasis, the existing regulatory regime also depends upon industry self regulation. In particular, the Canadian Petroleum Association's (the "CPA") Environmental Code of Practice and the detailed "Environmental Operating Guidelines", constitute a comprehensive guide to specific environmental laws and recommended industry operating procedures relating to environmental impacts of all stages of oil and gas industry operations.

\section{EMERGING ISSUES}

The Review Panel on Environmental Law Enforcement (the "Review Panel"), in its recent report entitled An Action Plan for Environmental Law Enforcement in Albert ${ }^{19}$ has suggested a shift in approach to environmental regulation in Alberta. It recommends the imposition of realistic emission limits in licenses, strict and vigorous enforcement, larger fines for breaches of license terms and personal liability of directors, officers and employees having a clear and direct involvement in a flagrant violation. This tougher approach is the philosophy behind the new generation of environmental statutes in other jurisdictions such as the federal Canadian Environmental Protection Act" ("CEPA") and the Comprehensive Environmental Response, Compensation and Liability $A t^{21}$ ("CERCLA") in the United States.

For a number of reasons, Alberta is likely to move towards similarly tough environmental legislation. There is a heightened societal concern for environmental issues arising out of incidents such as the Valdez tanker spill and the Lodgepole sour gas well blowout. Also, industry activity in the province is increasingly located in environmentally sensitive areas. Examples include drilling on the eastern slopes of the Rockies, the development of the Caroline sour gas field, production from other sour gas fields near urban communities and the heavy oil and in situ oil sands developments.

To the extent that Alberta does not modernize its environmental statutes of its own accord, it is likely that the federal government will occupy the field. The anti-dumping provisions of the federal Ocean Dumping Control Act ${ }^{22}$ (now contained in the new CEPA) were recently held to be within the federal government's legislative competence under its peace, order and good government power, the

19. Available from the Department of the Environment.

20. S.C. 1988, c. 22.

21. (1980) 42 U.S.C. $\S \S$ et seq.

(1987 Cumm. Ann. Pocket Part) or

(1980) Pub. L. 96-510 94 Stat. 2767.

22. S.C. $1974-75-76$ c. 55 . 
control of pollution being of national importance. CEPA attempts to regulate the entire field with respect to toxic substances in Canada. Provinces having equivalent legislation and standards will be exempted, but non-equivalent provincial legislation may be overridden if federal competence is upheld.

For example, the federal Environment Minister has recently announced that within the next five years he will put in place stringent regulations under CEPA and the federal Motor Vehicle Safety Act to control emissions from internal combustion engines that burn fossil fuels. This tougher legislation, which would be applicable to compressors and other industrial engines as well as to vehicles, would reduce, by up to 30 percent, emissions of nitrogen oxides and volatile organic compounds, cap carbon dioxide emissions and reduce toxins produced in the use of motor fuels.

As another example, Canada is a party to the International Sulphur Dioxide Protocol and has committed to a thirty percent reduction in sulphur emissions by 1993 . If provinces are lax in their regulatory initiatives, it is likely that the federal government will intervene under CEPA to achieve this international obligation.

\section{IMPLICATIONS FOR DRAFTING AGREEMENTS}

The prospect of the implementation of tougher laws in Alberta in the near future and the increasing likelihood of vendors, lenders and operators being subject to environmental litigation have increased awareness of the potential legal liabilities arising from environmental damage. As a result, commercial draftsmen are focusing greater attention on the various means available to operators and owners of environmentally sensitive oil and gas related assets to limit their environmental liabilities through environmental audits and other due diligence techniques, specific environmental representations, warranties and indemnities and other contractual techniques, risk assessment and insurance.

\section{THE EXISTING ALBERTA REGULATORY ENVIRONMENT}

Numerous federal and provincial statutory and regulatory provisions have direct and indirect environmental implications for the oil and gas industry in Alberta. This discussion focuses only on laws directly applicable to oil and gas industry operations. Attached as Appendix " $A$ " is a list of relevant federal and provincial environmental legislation.

Alberta Environment is extensively involved in the ERCB review process. In general, all applications with environmental impact are forwarded to Alberta Environment for its review of environmental concerns. Specific examples include applications for approval for major facilities and pipelines which by their size and location create environmental concerns. For example, ERCB Information Letter II 08-72-20 provides that an application to construct a gas processing plant should be filed with the ERCB, with a copy to Alberta Environment. After Alberta Environment reviews the application, it may also forward the application to other interested departments such as the Department of Agriculture, the Department of Forestry, Lands and Wildlife, the Department of Transportation, the Department of Energy, the Department of Culture and Multiculturalism and the Department of Municipal Affairs. This process of funnelling the environmental concerns of the Alberta Government through the ERCB is known as the "one window" process. 
After the relevant governmental departments review and assess the application, they will advise Alberta Environment of their concerns, if any. Alberta Environment will notify the ERCB of all governmental concerns regarding the application. Typically, the ERCB will then send a deficiency letter to the applicant setting out the concerns raised by Alberta Environment and advise the applicant to respond to them. These concerns are usually addressed to Alberta Environment's satisfaction and environmental concerns are seldom the sole reason an ERCB hearing will be held with respect to an application.

If a hearing is held, Alberta Environment will often be registered as an intervenor and will cross-examine the applicant. Although permitted to do so by section 26 of the ERCB's Rules of Practice, Alberta Environment rarely gives evidence at a hearing. The ERCB considers any concerns raised by Alberta Environment and is unlikely to grant an application in the face of serious environmental concerns.

\section{A. CLEAN AIR ACT AND CLEAN WATER ACT}

In theory, environmental requirements for all oil and gas facilities which discharge effluents or otherwise pollute the air or surface or ground water are regulated under the Clean Air Act and Clean Water Act. In practice, however, pursuant to ERCB Information Letter IL 86-2, facilities such as sweet gas plants and compressor stations are exempt from sections 3,4 and 5 of the Clean Air Act and the Clean Water Act if certain requirements are satisfied. ${ }^{23}$

Where the Clean Air Act and the Clean Water Act are applicable, they regulate by means of a scheme of construction permits, operating licenses and directives issued by the provincial Director of Standards and Approvals. The terms of approvals and licenses are negotiated between the applicant and Alberta Environment and are fixed for five year terms.

23. IL 86-2 describes criteria for the exemption of certain types and sizes of sweet gas processing plants from approval requirements under the Clean Air Act and Clean Water Act. A sweet gas plant is exempt from sections 3, 4 and 5 of the Clean Air ACt if its total oxides of nitrogen (NO, emissions are equal to or less than $16 \mathrm{~kg} / \mathrm{hr}$. Intermittent $\mathrm{NO}_{x}$ emissions from standby equipment and equipment used for emergency purposes may be omitted from the total $\mathrm{NO}_{\mathrm{x}}$ calculation. Any subsequent expansion or modification to a sweet gas plant that results in the total $\mathrm{NO}_{\mathrm{x}}$ emissions exceeding $16 \mathrm{~kg} / \mathrm{hr}$ will render the plant subject to the approval requirements of the Clean Air Act.

A sweet gas plant is exempt from sections 3,4 and 5 of the Clean Water Act if the following criteria are met:

(a) no industrial landfill on site;

(b) no sewage produced, or any sewage which is produced goes to a pit-type toilet, sewage field, leaching cesspool, or municipal plant;

(c) no discharge of process liquids, waste liquids, or produced water to the surrounding watershed;

(d) all above ground tanks for the containment or treatment of process water, wastewater, waste liquids, sewage, or produced water must be diked;

(e) no on-site pits, ponds, or lagoons for the containment or treatment of liquids, except flare pits or other small pits which comply with the Oil and Gas Conservation Regulations;

(f) no wastewater irrigation on site; and

(g) minimal probability of spills or leaks which would contaminate surface nunoff water, groundwater, or soil.

These criteria supercede the requirements for licensing and operation of sweet Class A plants as outlined in the "Gas Processing Waste Water Management Standards", September 1973 issued by Alberta Environment. 


\section{Clean Water Act}

Sections 3 and 4 of the Clean Water Act require that permits and licenses be obtained before the construction and the operation of plants which may contribute to water pollution. Failure to obtain a proper license or to operate within the terms of a license can result in a control order, a stop order or prosecution under the Act.

Alberta Environment monitors aquatic effluents and enforces the statute through investigations in response to specific complaints. Compliance is negotiated through technical discussions between Alberta Environment and the licensee and by administrative directives. Pursuant to section 14 of the Act, the Director of Pollution Control may issue water quality control orders if a water facility is considered to be the source of a water contaminant. The control order may direct the owner or operator of the facility to eliminate or limit the contaminant discharge or to install, replace or alter equipment designed to control or eliminate the discharge. Failure to comply is an offense subject to a maximum fine of $\$ 25,000$ or 3 months imprisonment in default of payment.

In addition, pursuant to section 15 of the Act, the Minister of Environment may issue stop orders requiring the recipient to cease operation. Failure to comply can result in a fine of up to $\$ 50,000$ per day or 12 months imprisonment or both. Prosecutions under the Act may be commenced within two years of the commission of the alleged offense but not afterwards.

The Minister may also apply to the Court of Queen's Bench by way of an originating notice for an order directing a person to comply with a stop order and failure to comply constitutes civil contempt. Further, an officer of the Department may without leave of the Court and without incurring liability for doing so, enter on any land and do any acts that are necessary to carry out the stop order. The Minister may recover any expenses incurred by the government in carrying out stop orders from the person to whom the stop order is directed.

\section{Clean Air Act}

Sections 3 and 9 of the Clean Air Act require that permits and licenses be obtained before the construction and the operation of plants which may contribute to air pollution. Alberta Environment monitors sulphur dioxide and hydrogen sulphide emissions under the Clean Air Act. Failure to obtain a proper license or to operate within the terms of a license can result in a control order, a stop order or prosecution under the Act.

Unlike the Clean Water Act, there is no provision allowing the Minister to take steps to carry out a stop order and charge the costs back to the offender.

\section{B. SEISMIC AND OTHER EXPLORATION ACTIVITY}

\section{Introduction}

Seismic testing and other exploration activity in Alberta is regulated by the Mines and Minerals Act and the Exploration Regulation passed pursuant to that Act. Under section 1(e) of the Regulation, exploration includes any operations on or over land 
or water to determine geologic or other conditions underlying the surface of land or water but excludes investigations by equipment operated in an aircraft or by a person on foot or in a vehicle using hand tools and previously established roads or trails. ${ }^{24}$

Section 151 of the Act prohibits any person from conducting exploration in Alberta unless he is the holder of an exploration license, the exploration is conducted under an approved exploration program and the exploration equipment is operated under an exploration permit. Section 153 of the Act gives the Minister of Forestry, Lands and Wildlife power to grant an exploration approval or exploration license on such conditions as he may prescribe.

\section{Geographic Limitations}

The Exploration Regulation prohibits seismic exploration involving the drilling of holes on certain environmentally sensitive lands including: in the Exploration Restricted Areas described in Schedule "A" to the Exploration Regulation; within an area where exploration is prohibited by an order of the Minister of the Environment under section 10 of the Land Surface Conservation and Reclamation Act; within a Restricted Development Area or Water Conservation Area established by regulation under section 15 of The Department of the Environment Act, where the use of the land in the Area for exploration is prohibited by a regulation under section 15 or 17 of that Act; and within a special planning area established by regulation under section 144 of the Planning Act, 1977, where the use of land in that area is prohibited by a regulation under that section..$^{25}$ The province has been divided into colour-coded areas depending upon the degree of the area's environmental sensitivity.

The Exploration Regulation also prohibits the conduct of exploration operations within prescribed distances of buildings, driveways, cemeteries, telephone lines, pipelines, wells and survey mounts. ${ }^{26}$

\section{Application}

Applications for exploration licenses are made to the Director of Forest Land Use accompanied by a preliminary plan and by a $\$ 1,000$ deposit as a guarantee that the applicant will comply with the obligations imposed by the Act. ${ }^{27}$

Where particular environmental concerns are involved, the application may be referred to other governmental authorities, for example, to the Director of the Land Management and Development Branch of the Public Lands Division for review, if the exploration program involves the use of public lands in the White or Yellow Areas and to the Department of the Environment for review if the exploration program involves the use of the bed or shore of a permanent watercourse or water body, or land within one kilometre of a dam.

In addition, where an application for exploration approval relates to a program of exploration on forested public lands (i.e., the Green Area), a copy of the

24. Alta. Reg. $423 / 78$, s. 2 .

25. Alta. Reg. $423 / 78$, s.4.

26. Alta. Reg. $423 / 78$, s. 24 .

27. Alta. Reg. $423 / 78$, s.11. 
application must be submitted to the superintendent of the forest in which the exploration will be conducted, and to the senior forest officer for the ranger district of that forest. Where an application for exploration approval relates to a program of exploration on public lands in the White Area or Yellow Area, a copy of the application must be submitted to the district supervisor of the Public Lands Division of the Department for the district in which the exploration will be conducted concurrently with the submission of the application to the Director of Forest Land Use.

The Minister may request a security deposit in respect of an exploration program in a prescribed amount and form. ${ }^{28}$ In assessing the need for and fixing the amount of a security deposit, the Minister must have regard to the content, circumstances and nature of the program of exploration and the location of the area to be explored.

\section{Operations}

The applicant must execute an exploration plan in the form approved by the Minister subject to any prescribed conditions. To ensure compliance, the regulations require that copies of the exploration approval be given to persons carrying out the exploration program on behalf of the applicant and to the crew operating the equipment utilized in the conduct of the program..$^{29}$ Further, before commencing an exploration program in a municipal district, county, special area or improvement district in the White or Yellow Area, the licensee must provide the administrator of the lands with notice of the commencement of the program and a copy of the approved preliminary plan.

Exploration operations may be conducted only in accordance with the approved program. For example, cut lines may be made only in locations authorized by the approved program. ${ }^{30}$ On public lands, a cut line may not be cleared to a width of more than 8 metres without the Minister's approval. ${ }^{31}$ Merchantable coniferous trees cut in the course of conduct of exploration on public lands within the Green Area must be decked and salvaged in accordance with the Timber Management Regulations.

The Forest and Prairie Protection Act and Regulations are applicable where field operations involve cutting and clearing of timber. In addition, pursuant to the Timber Management Regulations under the Forests Act, a person clearing land for industrial use must take all necessary precautions to minimize soil erosion and to avoid pollution of waters and waterways and must keep records of all timber produced, sold or transported. ${ }^{32}$

28. Alta. Reg. $423 / 78$, s. 16 .

29. Alta. Reg. $423 / 78$, s. 17 .

30. Alta. Reg. $423 / 78$, s. 23 .

31. Alta. Reg. $423 / 78, \mathrm{~s} .40$.

32. Specifically, a person clearing land in the green area for industrial purposes must do so in accordance with Timber Regulations which provide that merchantable coniferous trees exceeding fifty feet in height must be cut, lopped of roots, branches and 20 foot tops and must be checked separately from other trees. Within 60 days of clearing the land the industrial operator must remove the decked timber and put it to some beneficial use or dispose of it by way of sale or gift. If the decked timber is not removed within 60 days of the site clearing, it is forfeited to the Minister. The regulations also set out the area that may be cleared for industrial uses. 
Within 60 days after completion of the exploration field operations, the licensee must file with the Director a final plan under the exploration program together with a copy of all logs for each test hole logged during the conduct of the program, together with all pertinent data. The final plan must consist of a map showing the location of the area that was explored, the means of access, the location of new cut lines, detours and campsites constructed, the places at which samples or measurements were obtained and/or holes were drilled, and each shot hole and its number. ${ }^{33}$

Each hole drilled in connection with seismic activity must be abandoned in accordance with instructions on hole abandonment issued from time to time by the Minister. ${ }^{34}$ Where the ground surrounding the hole or excavation subsides, the licensee must promptly take necessary restorative steps once the subsidence is reported or otherwise becomes known to him.

The Exploration Regulation also provides for: reporting and repairing of property damaged by operations; operations on or near roads; and the release of water or gas from an acquifer or stratum which comes to the surface during drilling. ${ }^{35}$

\section{Penalties}

Where an exploration program is not being conducted in compliance with the Exploration Regulation or the conditions of the exploration approval, the Minister may declare any security deposit held to be forfeited or may expend such portion of the deposit as is necessary to remedy the non-compliance.$^{36} \mathrm{In}$ addition, the Minister may, under section 154 of the Mines \& Minerals Act, cancel an exploration license or an exploration permit if the licensee or permittee contravenes the portion of the Act or regulations relating to exploration or fails to comply with any condition of an exploration approval, license or permit.

\section{EXPLORATION AND DEVELOPMENT DRILLING}

The selection, design, construction and operation of drilling sites is regulated under the Oil and Gas Conservation Act and the Oil and Gas Conservation Regulations. Under the Act, the ERCB may refer any proposed operations to the Minister of the Environment for approval and any conditions imposed by the Minister must be imposed by the ERCB.

An application for a licence must be accompanied by a plan showing the location of the proposed well, the general character of the topography, any predominant drainage pattern and the well location relative to surface improvements and other wells.

\section{Well Licensing}

In licensing wells and approving well locations, the ERCB takes into consideration potential risk to local populations, the impact on the environment, the avail-

33. Alta. Reg. $423 / 78$, s.19.

34. Alta. Reg. $423 / 78$, s.36.

35. Alta. Reg. 423/78, ss.28-32.

36. Alta. Reg. $423 / 78$, s. 16 . 
ability of equally acceptable alternatives, and the net economic benefits to be derived. Other considerations include such factors as safety equipment and practices, detection equipment, contingency plans, aesthetically compatible structures, dikes and containment works, and insurance held by the applicant.

\section{Containment and Disposal of Waste Materials}

A number of waste materials are used or generated in the drilling process. ${ }^{37}$ The general obligation of the licensee of a well is to ensure that drilling fluids as well as water, rubbish, debris, oil waste, sand tailings and other products from the well are contained and disposed of so that no air, soil, surface water or underground source of potable water is polluted.

The ERCB has published new guidelines for the disposal of drilling wastes and fluids. The new guidelines require mandatory intensive sampling and testing of fluids and sumps for toxic levels and new load limits for disposal. The old regulations ${ }^{38}$ required testing of only those sumps that were disposed of off-lease and were over 600 pounds.

\section{(a) Storage}

The Oil and Gas Conservation Regulations regulate the storage of oil and other fluids. For example, oil may not be stored in pits under any circumstances and written approval of the ERCB is required to store crude bitumen or hydrocarbon in pits. ${ }^{39}$ Each tank at a battery or processing plant containing oil or any fluid other than fresh water must be surrounded by a dike or firewall of a net capacity greater than that of the largest tank within the dike or firewall, or such greater capacity as the ERCB may require. In addition, each oil tank at a well, production battery or processing plant must be located more than 60 metres from any surface improvement other than a public roadway unless the ERCB permits otherwise. ${ }^{40}$

Earthen pits used to store liquid wastes from drilling or servicing operations must be excavated to the depth to which they may be filled with liquid. An earthen pit used for the storage or disposal of water produced from a well, battery or a processing plant must be constructed of an impermeable material, have a surface area of not more than 300 square metres and be located so that it will not collect natural run-off water. Where the surface topography is not amenable to construction of a satisfactory earthen storage pit, the licensee of the well must contain liquid waste in tanks.

\section{(b) Control of Fluids}

The licensee and operator of a well must conduct operations so that oil, gas and water encountered are effectively controlled through the use of casing and control

37. For example, a wide variety of drilling fluids composed of water, clay, drill cuttings and chemicals used to control drilling conditions are circulated down the drill sting and retumed to the surface during drilling. In particular, current drilling practices involve the use of more additives than was traditionally the case, such as potassium chloride and diesel-based drilling fluids.

38. ID - OG 72-2.

39. Alta. Reg. $151 / 71$, s.8.010 \& s.8.020.

40. Alta. Reg. 151/71, s.8.030. 
equipment. ${ }^{41}$ The regulations generally require that the licensee maintain minimum surface casing and not drill beyond certain depths unless intermediate casing is set. ${ }^{42}$

Wells may not be drilled, and associated pits for containing mud, oil, water and other fluids associated with a well may not be constructed, closer than 100 metres from the normal high water mark of a body of water or a permanent stream, except with written ERCB approval. ${ }^{43}$ Where a well or battery is located closer than 100 metres from the normal high water mark of a body of water or permanent stream, such that a spill may reach the water, the licensee or operator must, if the well is not on a pump, install a valve on the well head which closes automatically to shut off an uncontrolled flow of oil from the well in the event of the failure of the well head, surface facilities or a gathering line. At the request of the ERCB, the licensee or operator must submit a plan to limit the spread of and to recover oil from the surface of the water in the event of a leak or spill. ${ }^{44}$

In general, where the ERCB believes that the location or condition of a well is such that it may become a source of serious water pollution, the ERCB may require that the well or battery be abandoned. ${ }^{45}$

\section{(c) Disposal of Water and Oil-Based Wastes}

The licensee of a well or the operator of a battery or processing plant must dispose of all water produced from a well in a manner satisfactory to the ERCB. The amount of water that may be disposed of is limited having regard to the salinity of the water, the nature of the soil and other circumstances. Any water in excess of the limit must be disposed of in accordance with a scheme approved by the ERCB under section 26 of the Oil \& Gas Conservation Act and by the Minister of the Environment.

Oil-based wastes, including waste oil sludge and oil spill debris, are regulated pursuant to ERCB Information Letter 85-16 which provides that all oily wastes must be deposited into an oily waste storage facility which has been approved by the ERCB prior to construction. Acceptable oily waste storage facilities include concrete lined pits; semi-buried metal tanks with impervious lining material; surface storage tanks with adequate dikes; and any other method which the ERCB feels will adequately contain oily wastes. All storage facilities must have drainage systems which allow for monitoring of leaks.

Further, the ERCB will no longer permit the use of earthen structures for temporary storage of oil wastes where the operator's permanent facilities have reached capacity. Such structures will only be approved by the ERCB in emergency situations such as large oil spills or serious equipment malfunction.

41. Alta. Reg. $151 / 71$, s.6.050.

42. Alta. Reg. $151 / 71$, ss.6.060-6.120.

43. Alta. Reg. $151 / 71$, s.2.120.

44. Alta. Reg. $151 / 71$, s.8.060.

45. Alta. Reg. $151 / 71$, s.8.070 


\section{(d) Control of Oil and Salt Water Spills}

Section 8.050 of the Oil and Gas Conservation Regulations deals with the control of oil and saltwater spills. The Regulations describe notification procedures and provide guidelines for the preparation of oil and saltwater spill reports.

When oil or saltwater is spilled from a well head, tank, separator, treater or processing vessel, the licensee of the well or operator of the facility must take immediate steps to contain and clean up the oil or saltwater and must ensure that the contaminated product is processed in the operator's facilities or sent to an approved waste processing and disposal facility. If the spill of oil or saltwater is not confined to the site or the volume is in excess of two cubic metres, the size and location of the spill must be reported to the ERCB. When requested by the ERCB, the report must be supplemented with additional information regarding the time of the spill, the circumstances leading to the spill, a discussion of the spill containment and recovery procedures, a discussion of steps to be taken to prevent similar future spills and an outline of the proposed spill site rehabilitation program.

Where the spill occurs while oil or saltwater is being transported by means other than a pipeline, the spill must be reported immediately to the ERCB and to the Department of the Environment. Steps must be taken to contain and clean up the oil or saltwater spilled and to ensure that the contaminated oil and saltwater is sent to an approved waste processing and disposal facility.

In addition, section 94 of the Oil and Gas Conservation Act confers broad powers on the ERCB to control an escape of oil or gas from a well, pipeline or battery. The Board may direct the licensee or pipeline operator responsible for the well, battery or pipeline from which oil escaped, to take steps necessary to contain and clean up oil which has escaped and to prevent further escape of oil.

Further, the ERCB may enter the spill area and conduct any operations necessary to contain and clean up oil which has escaped. The ERCB may recover and dispose of spilled oil as if it were its own property and, if sold, apply the proceeds to pay the costs and expenses of its operations. If the costs and expenses determined by the ERCB are not fully paid from the sale of oil recovered or by the persons directed by the ERCB to pay them, the ERCB may direct that the balance of the costs and expenses be paid by the licensee of the well.

Under section 95 of the Act, the ERCB may take any steps and employ any persons it considers necessary to take possession of any well, together with property used in connection with the well for the enforcement of any order made by it. The ERCB may either discontinue all production or take over the management and control of production from the well, and take any steps it considers necessary to prevent the flow or escape of oil, gas, crude bitumen or water. On taking possession of any well, the ERCB may deal with and dispose of all oil, gas and crude bitumen produced at the well as if it were its property and apply any proceeds of sale to pay its costs and expenses.

\section{Air Pollution Control}

Unless a licensee has obtained written approval from the ERCB, the licensee may not bum oil, gas, oily waste or other material produced or used at a well except 
where there is no significant or visible emission of smoke, in emergency situations or due to equipment failure. ${ }^{46}$ There are specific regulations dealing with sour gas. ${ }^{47}$

\section{Blowout Prevention Plans}

The Oil and Gas Conservation Regulations also regulate blowout prevention procedures by prescribing the equipment that must be installed by the well licensee, specifications for the equipment used, the arrangement of various systems including the kill system and the bleed-off system and prescribe blowout prevention steps taken during operations. The regulations also impose strict requirements for crew training and qualification including the performance of regular blowout prevention drills.

\section{Penalties}

Under section 92(1) of the Act, if the ERCB is of the opinion that the control of a well or any completion, suspension or abandonment is not in accordance with an order, direction or requirement of the ERCB, a person authorized by ERCB may enter the well site and do whatever the ERCB considers necessary. The costs of the work are determined by the ERCB, and the Provincial Treasurer may use or expend all or any part of the licensee's deposit to reimburse the ERCB for those costs. Costs remaining unpaid after the application of the deposit are a debt payable by the licensee to the ERCB.

To cover such expenses the ERCB may sell or otherwise dispose of any drilling or producing equipment, installation or material found on the well site or taken from the well, unless it knows such equipment is owned by someone other than the licensee of the well. On receipt of sale proceeds, the ERCB must apply the money, first in payment of any costs that remain unpaid after applying the deposit

46. Alta. Reg. 151/71, s.7.040.

47. Where the hydrogen sulphide concentration in a well exceeds 50 moles per kilomole, the well is not on pump, and is located within 800 metres of an occupied dwelling or within 8 kilometres of the limits of a city, town or village and has the potential to produce more than 140 thousand cubic metres of gas per day, the licensee must install a valve in the tubing of the well that may be controlled from the surface and which will close automatically in the event of an uncontrolled flow of oil or gas or failure of the system which operates the valve. Alta. Reg. 151/71, s.7.050.

Where a well produces gas containing more than 10 moles per kilomole of hydrogen sulphide, and a flare line is installed at the gas well for burning gas produced during normal depressurizing operations or other routine flaring, the licensee must provide a flare stack constructed in accordance with prescribed specifications. Where a pressure release valve, rupture disc or burst plate is installed on a separator or dehydrator or other pressure vessel which receives production from such a gas well, the valve, rupture disc or burst plate fitting must be connected to the flare stack. Where gas is produced from the well during any test, cleaning operations or well servicing operations, the licensee must obtain written approval from the ERCB of the method, stack height and equipment to be used to flare the gas. Where liquids are produced from the well during any test, cleaning or servicing operations, the liquids must be separated and piped to a storage tank and all gas must be discharged through an approved flare stack. Unless the licensee equips and operates the well so that the maximum operating flow line gauge pressure cannot exceed 200 pounds per square inch gauge, the licensee must install a valve on the wellhead which closes automatically in the event of an uncontrolled flow of oil or gas. At the request of the ERCB, the licensee of such a well must also file an outline of emergency procedures to ensure public safety in the event of an uncontrolled emission of oil or gas. Alta. Reg. 151/71, s.7.060. 
and the remainder to the Provincial Treasurer for payment out to persons who have filed claims within six months of the sale and who are entitled to receive it.

\section{CONVENTIONAL OIL AND GAS PRODUCTION FACILITIES: GAS PLANTS, COMPRESSOR FACILITIES AND BATTERIES}

\section{Introduction}

The typical gas plant location includes gas treating facilities to remove liquids and acid gas from raw gas, facilities to extract sulphur from acid gas, storage tanks for gas liquids and an area for sulphur block storage and loading. Other facilities include those for the containment, treatment and disposal of water produced in association with oil and gas, detention lagoons, settling ponds and subsurface disposal facilities.

A variety of waste materials which may result from natural gas processing include: holding pond sludges, process filters, spent iron sponges, boiler water, cooling tower blowdown, glycol, desiccants, catalysts, degradation products from a mine and sulfinol treating and waste sulphur.

\section{Approvals and Permits}

Section 26 of the Oil and Gas Conservation Act requires that any scheme for a gas processing plant be approved by the ERCB. In addition to ERCB approval, if, for example, the plant is a sour gas plant or other major environmentally sensitive facility, a permit to construct and a licence to operate must be obtained from Alberta Environment, as applicable, under the Clean Air Act and the Clean Water Act.

Under the industrial development permit provisions in Section 30 of the Act, the ERCB exercises jurisdiction over the construction and operation of petrochemical facilities in the province. Any use of an energy resource produced in Alberta as a raw material or fuel in any industrial manufacturing operation requires an industrial development permit from the ERCB.

\section{Construction}

The site selection, design, construction and operation of a primary gas plant or battery is regulated pursuant to the regulations to the Act. The regulations require that an application for approval must be made to the ERCB prior to the construction of a battery, primary gas plant or compressor facility. In addition, a number of ERCB Interim Directives and Information Letters are relevant. ${ }^{48}$

48. ID $87-2$

Minimum Distance Requirements Separating Proposed Sour Wells from Residential and Other Developments

IL-OG 76-24 Stack Exit Temperatures for Acid Gas Incinerators Associated with Gas Processing Plants

IL 79-16 Revised Incinerator Stack Exit Temperature Criteria for Plants Processing Sour Gas

IL $80-24$

IL $80-30$ Sulphur Recovery Guidelines-Gas Processing Operations

IL $84-11$ Application for Approval of Natural Gas Compressors

IL $85-16$ Approval, Monitoring, and Control of Sulphur Storage Sites

L 86-2 Storage, Handling, and Disposal of Oily Wastes Criteria for Exemption of Sweet Gas Processing Plants - Clean Air Act and Clean Water Act. 
The regulations prohibit construction of a new processing plant or a major modification to an existing gas plant until the ERCB and the Minister of the Environment have approved the location, conservation levels and pollution control features of the scheme, and, if required, the Director of Standards and Approvals of the Department of the Environment has issued a permit to construct the necessary facilities pursuant to the Clean Air Act and the Clean Water Act. ${ }^{49}$ Commencement of processing operations is prohibited until operating approvals have been obtained from the same agencies. ${ }^{30}$

\section{Application}

The regulations provide details respecting structuring and content of applications for gas plant construction and operating approvals. ${ }^{\text {s1 }}$ In general, the application must contain information on plant location, topography of the area, location of lakes and streams, location of occupied buildings within an eight kilometre radius of the plant, location of other plants, and a description of general land use in the area. The application must discuss methods proposed to control hydrocarbon vapour emissions, sulphur dust, smoke, odours and noise, the monitoring program for hydrogen sulphide and sulphur dioxide emissions and methods for containing, treating and disposing of water produced in association with oil and gas.

Gas containing hydrogen sulphide cannot be discharged from the plant to the atmosphere unless it is burned so that essentially all of the sulphur is converted to sulphur dioxide. ${ }^{52}$ Where the plant is processing gas containing more than 10 moles of hydrogen sulphide per kilomole of hydrogen, the operator must file with the ERCB and the Department of the Environment an outline of emergency procedures to ensure public safety that will be followed in the event of an uncontrolled release of contaminants to the air, water or land from the processing plant. ${ }^{53}$ The terms of such emergency response plans are of particular concern to the industry, since the requirements have recently become more onerous. There is a tendency for features offered by one applicant to become features thereafter strongly recommended or required by the ERCB in subsequent applications. In particular, the industry has questioned the cost-efficiency of some proposals such as installation of siren waming system, the use of radios to divert school buses and the provision of personal air monitors to residents in close proximity to a site. Consequently, the

49. Alta. Reg. $151 / 71$, s.9.030; $71 / 74$.

50. Alta. Reg. $151 / 71$, s.9.030; $71 / 74$.

51. Alta. Reg. $151 / 71$, s. $15.050 ; 69 / 72 ; 71 / 74 ; 179 / 76 ; 229 / 79 ; 326 / 79$. The ERCB has also issued several Interim Directives and Information Letters on pollution control design requirements including IL OG 76-24, IL 79-16 and IL 80-24.

52. Alta. Reg. 151/71, s.9.050; 71/74.

53. If a storage battery will emit hydrogen sulphide at a concentration exceeding 10 moles per kilomole in a representative sample, under section 7.070 , the operator of the battery must erect suitable signs at the entrance to the battery waming of the presence of poisonous gas. In such circumstances, tank vapours must be discharged from a flare line meeting specifications established in section 7.060 of the Regulation and burned so that essentially all sulphur compounds are converted to sulphur dioxide so as to ensure that the average concentration of hydrogen sulphide and sulphur dioxide in the ambient air does not exceed the maximum permissible concentrations set out in the Clean Air (Maximum Levels) Regulations under the Clean Air Act. Section 8.170 of the Regulation requires fencing of the battery. Section 7.060 requires that pressure relief valves, rupture disks and burst plates installed on a separator or dehydrator be connected to a flare stack. 
formation of an industry committee to standardize emergency response plan submissions is now under active consideration.

\section{Recent Developments}

In a speech on June 9, 1989, Frank Mink, a member of the ERCB, stated the ERCB's position on gas plant proliferation in the province. Currently, there are 225 sour gas plants and 380 sweet plants in the province having a raw gas inlet capacity of about 18 billion cubic feet per day. The ERCB is concerned by the fact that the average annual throughput of these plants is only about 45 per cent of capacity and that even during the peak winter months the throughput is only about 55 percent.

Under the Oil and Gas Conservation Act, ERCB approval is required to proceed with construction of new gas processing plants. Under the Energy Resources Conservation Act, the ERCB in granting such approvals must make sure that its decisions foster energy developments that are economic, orderly and in the broad public interest.

In his speech, Mr. Mink made it clear that given the ERCB's current serious concern with gas plant proliferation, the Board expects "to take a more critical view of any new application, particularly if public opposition is evident"'.

In particular, the ERCB must be convinced that the new plant is necessary and that the rationalization of existing capacity is not a preferred alternative considering the impact of the facilities on surface disturbance and people affected by the activity.

In permitting new gas plants, the ERCB will take into account the following factors:

(1) The ERCB will require a detailed economic analysis demonstrating that it would be more economic, including in the calculation social and environmental consequences, to build a separate new plant than to expand an existing plant and to pipeline the raw gas to it.

(2) The ERCB will not consider an applicant's desire to retain ownership or control of a processing facility as a reason in itself to approve an application. In fact, the ERCB regards the notion of each owner processing his own gas as the root cause of the plant proliferation problem.

(3) In considering new plants, superior capabilities for sulphur and liquids recovery is an important consideration.

(4) The ERCB views the absence of firm capacity on a Nova lateral to an existing plant as a short-term constraint since Nova has committed to give special consideration to these situations. If drainage is occurring because of the lack of firm transportation to an existing plant, an owner should seriously consider the option of recourse under the statutory provisions for common carriers, purchasers and processors.

(5) The fact that expansion of an existing plant may require compliance with the province's more stringent guidelines for larger sour gas plants is not regarded as material by the ERCB.

(6) The need for a new plant to accommodate future drilling must be firmly established to convince the ERCB that this is a genuine important factor. 
(7) Where a user of an existing plant feels that custom processing fees are too high, his recourse is not to the ERCB but rather to the Public Utilities Board which has jurisdiction, under the Gas Utilities Act, to hold an investigation and to allow or change any tolls for gas utilities which in its opinion are excessive, unjust or unreasonable or unjustly discriminate between different persons.

\section{E. WATERFLOOD PROJECTS}

The main environmental concern in undertaking waterflood projects is the development and use of water supply. The legislation governing water usage and water quality in Alberta includes the Water Resources Act, the Ground Water Development Act and the Clean Water Act.

Under the Ground Water Development Act, no person can drill a water well unless he is the holder of a subsisting license issued by a Director appointed by the Minister of Environment, or unless he is the owner of the land on which the well is to be located and the water from the well is to be used solely for that individual's domestic or agricultural purposes.

The Director has the power to enter land to inspect any well and may declare a well a problem well and require that the well be abandoned. Further, if at any time the flow of water from the well is not in control, the Director may enter on land and do what is necessary to control the flow. The Director may recover costs of work done by the person responsible for the flow or abandonment of the well.

Under the Water Resources Act, the ownership of all water in the Province of Alberta resides with the Crown and water cannot be diverted and used without prior approval. Any person proposing to use groundwater or surface water for nondomestic purposes must obtain authorization from Alberta Environment in the form of a licence or temporary permit. ${ }^{54}$ The applicant must demonstrate that sufficient water is available for the project and that diversion of the required amount of water will not have an unreasonable effect on wells in the surrounding area.

\section{F. OIL SANDS}

\section{Introduction}

The ERCB regulates the approval process for projects involving the recovery of oil sands and crude bitumen under the Oil Sands Conservation Act. Projects involving the recovery of oil sands and crude bitumen include in situ operations (schemes or operations using wells for recovery) and mining operations (including surface or underground operations). As well, the ERCB regulates the processing and use of oil sands and crude bitumen.

54. The preferential onder of water use under the Act is domestic purposes, municipal purposes, irrigation and other purposes, industrial purposes and other like purposes. 
In situ heavy oil projects raise a number of special environmental concerns. ${ }^{5 s}$ Site selection is important because of the extensive site disturbances caused by in situ projects. Heavy oil projects generate high volumes of oil wastes, used drilling muds and lime sludges. Wastes generated from the heavy oil process include wastes from production facilities and drilling operations, solids eroded from oil reservoirs and separated in settling tanks, saltwater separated from crude oil, waste crude oil, waste sludges and oil spill debris.

With respect to gaseous emissions, annulus vent gases are the major unique concern associated with in situ heavy oil projects. Annulus vent gases are a result of thermal recovery technology and contain not only hydrogen sulphide $\left(\mathrm{H}_{2} \mathrm{~S}\right)$ but also PNA's and sometimes chlorinated hydrocarbons. Because heavy oil projects use large amounts of water for drilling and thermal processes, contamination of groundwater acquifers and surface water is a concern. Other problems include the restrictions to wildlife movements caused by the large number of above-ground pipelines, the high volume of vehicle traffic and the large scale reclamation that needs to be done.

\section{Approval}

Pursuant to section 7 of the Oil Sands Conservation Act, the ERCB may designate a scheme or operation as an in situ operation or mining operation and may declare any hydrocarbon substance, except natural gas and coal, to be oil sands, if the ERCB is satisfied that to do so would be in the interest of the orderly, efficient or economic development of the hydrocarbon substances or oil sands. Section 10 of the Act prohibits the undertaking or operation of a scheme for the recovery of oil sands or crude bitumen unless the ERCB, on application, has granted approval. Similarly, section 11 of the Act prohibits any person from constructing or operating a processing plant without ERCB approval.

Under the Act, the ERCB is not required to hold a hearing in respect of an oil sands recovery application or a processing plant application, however, the ERCB may, on receiving an application under section 10 or 11 , make investigations or inquiries and hold any hearings that it considers necessary and desirable in connection with the application.

55. The ERCB has prepared a number of Interim Directives (ID) and Informational Letters (IIL) regarding environmental concerns for in situ projects. Relevant ID's and IL's are as follows:

ID-OG 75-2 Sump Fluid Disposal Requirements

ID 81-1 Subsurface Disposal of Drilling Fluids

IL 84-7 Declaration of Oil Sands Areas to Facilitate Orderly Leasing and Stable Regulation

IL 85-12 Oil Sands Primary Production: Well Spacing Primary Recovery Scheme Approvals

IL 85-16 Storage Handling and Disposal of Oily Wastes

IL 86-9 Approval Procedures for Single Well Steam Stimulation Test in Oil Sands Areas.

In addition, the ERCB has prepared a document entitled "The Lindbergh Oil Sands Area" (ENERFAX Factsheet No. 5) which discusses the bitumen recovery process, in situ operations and environmental concerns pertinent to the Lindbergh Area. In addition two handbooks are available from the ERCB or Alberta Environment: "Oil Sands Guidelines - ERCB Application" and "Development and Declaration Applications for In Situ Oil Sands Schemes". 
After reviewing the application, the ERCB may, with the prior authorization of the Lieutenant Governor in Council, grant an approval on any terms and conditions that the ERCB or Lieutenant Governor in Council consider appropriate. Prior authorization of the Lieutenant Governor in Council is not required in certain circumstances as set out in section 10 .

Applications under section 10 or 11 are referred by the ERCB to the Minister of the Environment and the Minister of Forestry, Lands and Wildlife for approval as to matters which may effect the environment. These Ministers may give their approval of the application with or without conditions.

\section{Permit}

Section 13 of the Act prohibits the use of crude bitumen or an oil sands product in an industrial or manufacturing operation unless the ERCB, on application, has granted an industrial development permit authorizing its use. A permit will not be required in certain circumstances as set out in subsection 13(2). It is within the ERCB's discretion whether or not to hold a hearing with respect to such an application. Again, any granting of a permit requires prior authorization of the Lieutenant Governor in Council. The ERCB shall not grant an industrial development permit unless in its opinion it is in the public interest to do so. 


\section{Application}

The Oil Sands Conservation Regulation ${ }^{56}$ prescribes the manner in which applications under the Act are to be made and specifies the information that is to be included in an application. Section 2 of the Regulation provides that an application made under the Act must include, where applicable, those requirements set out in a guide published by the ERCB for those applications. ERCB Guide G-3 requires that all applications for commercial projects for recovery of oil sands and crude bitumen include a brief summary of all aspects of the project, technical and related economic details as well as assessments of biophysical impact, social impact and a cost-benefit analysis. Additional information may be required in particular situations. A subsequent information letter issued by the ERCB (1L 85-12) requires that an application under section 10 of the Act also include statements concerning environmental protection measures including noise suppression, water, sand and oily waste disposal and water management plans for drainage.

\section{Penalties and Enforcement}

Under section 16 of the Act, a non-complying operator or permittee may have its approval cancelled by the ERCB, with the prior authorization of the Lieutenant Govemor in Council. Further, under section 9, if there is non-compliance in respect

56. The Regulations regulate all aspects of recovering and processing oil sands and crude bitumen. Under the Regulations, ERCB approval is required to commence, modify, suspend or abandon oil sands sites, in situ operations, mining operations and processing plant operations. As well, the Regulations also prescribe the methods, equipment and materials to be used in construction, operation and abandonment of an oil sands site. The Regulations also provide for the use, storage, waste and disposal of crude bitumen and hydrocarbon substances deemed to be oil sands under the Act.

The Regulations dealing with reporting and recording requirements are of particular importance to operators. These Regulations contain several provisions setting out which records and reports must be submitted to the ERCB at prescribed times as well as the reports and records that must be kept by holders of approvals and permits. Part 3 of the Conservation Regulation sets out the reporting requirements for mining operations; Part 4 sets out the reporting requirements for in situ operations; and Part 5 sets out the reporting requirements for processing plants. In general, these sections require filing reports on daily, monthly and yearly basis. Violation of the regulations can result in the suspension of approvals and permits.

On a more general level, the regulations prescribe pollution and safety control measures to be employed in operation of oil sands sites and prescribe the procedures to be followed in the event of spills, fires and damage involving oil sand sites. Special requirements are prescribed for oil sands sites producing gas with a hydrogen sulphide of greater content of greater than 10 moles per kilomole of natural gas. In particular an operator of such a site is required to file an emergency response plan with the ERCB dealing with the procedures to be followed when handling gas with a hydrogen sulphide content greater than 10 moles per kilomole of natural gas. As well, all operators must file emergency response plans setting out in the procedure to be utilized in the event of an uncontrolled emission of contaminants into the air, water or land.

Section 13 of the Regulation prescribes the procedure to be followed in the event of a spill, fire or damage. An operator must report to the ERCB any liquid spill, break or leak in a vessel or gathering line or other equipment that occurs at an oil sands site where the loss exceeds 2 cubic metres of liquid hydrocarbon or 30,000 cubic metres of gas or gas equivalent and any fire that occurs at an oil sands site. The ERCB may also direct that the operator report the quantity of liquid, gas and gas equivalent lost, the time the event occurred, the description of the circumstances leading to the event, the actions taken in response to the event and an outline and schedule for spill site or fire site rehabilitation. 
of any construction or operation at an oil sands site the ERCB may issue a stop order suspending the construction or operation in whole or in part. Where a stop order is made, the ERCB must hold an inquiry within a reasonable time of making the order to investigate the circumstances leading to the making of the order. After the inquiry, the ERCB can either renew or rescind the order or take any other action or make any other order it considers to be warranted by the circumstances.

Section 20 of the Act empowers the ERCB to take remedial action where the operation of an oil sands site is not in compliance and charge the holder of the approval with the remedial costs.

\section{G. PIPELINES}

\section{Introduction}

In general, the construction and operation of pipelines situated wholly within Alberta is governed by the Pipeline Act ${ }^{57}$ and the Pipeline Regulation. The Pipeline Regulation constitutes a regulatory code covering all phases of pipeline construction and operation including standards and requirements for design, construction, testing, operation, maintenance and repair of pipelines. Pursuant to section 7 of the Pipeline Act, a permit from the ERCB is necessary to construct a pipeline in the Province of Alberta. The permit is obtained by making application to the ERCB in accordance with the regulations. Section 19 of the Pipeline Act prohibits the operation of a pipeline on a permanent basis without a licence from the

57. In addition to the Pipeline $A C l$, in specific circumstances involving the operation of a pipeline, other acts may apply and the applicant may be required to obtain approvals regarding the pipeline from other agencies. For instance, pipelines with diameters greater than $150 \mathrm{~mm}$ and lengths greater than 16 kilometres, require Development and Reclamation Approval under the Land Surface Conservation and Reclamation Act and the regulations thereunder including the Land Conservation Regulations and the Regulated Oil and Gas Surface Operations Regulations as well as under the Restricted Development Area Regulations pursuant to Section 15 of the Department of Environment Act.

As well, the Alberta Historical Resources Act provides the Minister of Culture with authority to require developers of pipelines and oil sands sites to prepare an historical resources impact assessment report detailing the nature and location of historical resource sites, the postulated effect of the development on each site, and the proposed mitigative measures to be undertaken by the developer to minimize loss to the site. This report is reviewed by the Historical Resources Division, Alberta Culture, prior to any land surface disturbance by the developer. The Historical Resources Division can request modifications to the report. Where the Historical Resources Division and the developer cannot agree on appropriate mitigative measures to be undertaken, the Minister of Culture will be responsible for the final decision. The developer will be responsible for all mitigative measures deemed appropriate at the historical resources site. Development will be permitted to proceed once the historical resource impact assessment report is deemed acceptable and the developer has carried out all mitigative measures.

In August 1982, the ERCB issued IL 82-11 in order to assist implementation of the Historical Resources Act. Under IL 82-11, the ERCB may request that developers making applications for permits, licenses or approval for major projects under statutes administered by the ERCB shall include, as part of their application, the results of an inspection of archaeological, paleontologi$\mathrm{cal}$, and historical resource sites that might be disturbed by the proposed development. An historical resource assessment may not be necessary in all instances. A developer can determine whether such a report will be necessary by consulting with the ERCB. Further, if a developer becomes aware of an apparent historical site during development, he must immediately notify the ERCB and take steps to ensure the site is preserved until its significance can be assessed by the Historical Resources Division, which must inspect such sites within 3 days of being notified by the ERCB. 
ERCB, however, pursuant to ERCB Interim Directive 85-2 a permit will authorize interim operation of pipelines subject to testing or approval of the ERCB. The ERCB may grant a licence to an applicant subject to any terms and conditions expressed in the licence.

\section{Application}

Under section 2 of the Pipeline Regulation, an application for a permit ${ }^{58}$ to construct a pipeline must include among other things a map showing the proposed pipeline, a statement that easements and consents of landowners have been obtained, and, if they have not been obtained, a list of concerned landowners. Under section 29 of the Energy Resources Conservation Act, the ERCB has an obligation to give any person directly and adversely affected by an application an opportunity to make representations to the ERCB in respect of the proposed pipeline.

In addition, an application for a permit to construct a pipeline to transmit sour gas must contain additional information regarding the chemical analysis of gas to be transmitted, a description of the leak detection system, evidence of emergency shut down services and a plan showing the location of individual dwellings, industrial and commercial developments and public facilities along the proposed route.

The ERCB must refer all applications to the Minister of the Environment and the Minister of Forestry, Lands and Wildlife for their approval, unless these Ministers otherwise direct. These departments may give their approval with conditions which the ERCB must then attach to the permit. The ERCB may also confer with the Gas Utility Board regarding any matter in the application and may have regard to the advice of the Gas Utility Board concerning any such matter.

The ERCB may grant a permit subject to any terms and conditions it stipulates. As well, the ERCB may prescribe the location and the route of the pipeline and the location of the pipeline right of way. The decision of the ERCB with respect to a permit is final and there is no right of appeal from the decision.

58. The ERCB has prepared a number of ID's and IL's regarding environmental concerns for pipelines. Relevant ID's and IL's are as follows:

ID 81-4 Proposed Wells and Pipelines Near Urban Centres

ID 85-1 Pipeline Permit and Licence Applications

ID 85-2 Changes to Pipeline Application and Approval Procedures

IL 80-11 Joint Use of Right-of-Way

IL 85-2 Leak Prevention and Detection

Section 5 of the Pipeline Regulations sets out what must be included in an application for a licence to operate a pipeline. Requirements include a statement that the pipeline was constructed in accordance with a permit, that it has been satisfactorily tested and a copy of the most recent Board Pipeline Base Map showing the constructed line. ERCB Interim Directive 88-2 requires an applicant for a proposed pipeline to advise both urban and rural authorities of its intent to apply for ERCB approval.

Alberta Regulation 135/72 provides that a pipeline laid through forested land must be buried at least 18 inches below the soil surface within 24 months from the time the pipeline is put into service. This time may be extended by application. Alta. Reg. 135/72 provides that where a forest fire is endangering a pipeline the operator is responsible for shutting off every well supplying the pipeline and depressurizing every pipeline located within a $1 / 2$ mile radius of fire. 


\section{Leaks or Breaks}

Section 36 of the Pipeline Act requires a licensee to immediately report any leak or break in a pipeline to the ERCB, and if a pipeline leaks on Crown land or in a forested area, also to the Department of Forestry, Lands and Wildlife. Section 37 of the Act regulates the clean up of spills and allows the ERCB to direct an operator or licensee to take steps to contain and clean up the substance and take steps to prevent further escape or to enter the area and conduct any operations it considers necessary to contain and clean up the substance and to prevent further escape. Where the ERCB enters an area to contain and clean up the escaped substance it may recover, deal with and dispose of the escaped substance as if it were the property of the ERCB. The ERCB may also determine the costs and expenses of the operations and direct by whom and to what extent they are to be paid. Unlike the analogous provisions in the Oil and Gas Conservation Act, there are no specific provisions which make the licensed operator of the pipeline ultimately responsible for the payment of the ERCB's costs of clean up. Section 54 of the Regulation requires that the permittee or licensee take immediate steps to stop the source of release of substances from the pipeline and contain and clean up the spills.

A licensee must, upon request by the ERCB after a leak or break, make a report to the ERCB outlining the time and cause of the leak, approximate quantity of substance lost, method of repair and steps to prevent future occurrences. If more than two cubic metres of substance escapes or if substances escape beyond the right of way, the ERCB may require additional information concerning spill containment and recovery procedures.

\section{Abandonment}

Under Part 6 of the Act, any discontinuance or abandonment of construction or operation of a pipeline may only occur with the consent of the ERCB except in an emergency or for repairs or maintenance or in the ordinary course of running the pipeline. An application for abandonment must include a description of the method to be used for removal or abandonment and arrangements for ownership of the pipeline after abandonment. The ERCB's consent to abandonment does not relieve the licensee or its assignee of other or further abandonment operations that may become necessary.

Sections 60 to 69 of the regulations describe the procedure that must be followed for the take-up, removal or abandonment of pipelines. ERCB consent is required for all pipelines and Development and Reclamation approval from Alberta Environment is required for the abandonment of a regulated pipeline.

\section{Operation}

Specific sections of the regulations require that a licensee develop and maintain a manual of operating and maintenance procedures for all licensed pipelines. In addition to this manual, the regulations require that a licensee of a pipeline transmitting gas containing more than 10 moles of hydrogen sulphide gas per kilomole of natural gas must maintain an emergency procedure manual for assessing emergency situations when there is an uncontrolled emission of gas, co-ordinating 
control measures in emergency situations and actions necessary to ensure public safety. This manual must be updated once a year and provided to ERCB upon request.

\section{Other}

There is no specific requirement in the Pipeline Act that a hearing be held on applications for either permits or licenses, however, the inquiry procedures coupled with the ERCB's general Rules of Procedure under the Energy Resources Conservation Act, are used to hold hearings on major applications. As well, the ERCB is empowered under section 5 of the Act to inquire into, examine or investigate any matter relating to economic, orderly and efficient pipeline development, safety in construction and operation of pipelines, and the control of pollution and conservation of the environment in the development and operation of pipeline facilities.

Under Part 5 of the Act, the ERCB can suspend construction or operation of a pipeline where there is a contravention of the Act, the regulations, a permit or licence or the method or practice employed or any equipment or installation at the pipeline is improper, hazardous, inadequate or defective. In these situations, the ERCB may call an inquiry to determine whether a permit or licence should be suspended. If a suspension order is issued, a further inquiry must be held to investigate the circumstances leading to the suspension. After the conclusion of an inquiry, the ERCB may allow operations subject to conditions, continue the suspension or cancel the licence or permit.

\section{H. SOUR GAS WELLS AND FACILITIES}

\section{Introduction}

The incidence of "sour gas" (natural gas containing hydrogen sulphide) during drilling, processing and transportation operations is of significant environmental concern to Alberta's oil and gas industry. Thirty percent of Alberta's total gas reserves are classified as sour and most of them are located in the corridor between Edmonton and Calgary. ${ }^{59}$ There are over 100 sour gas processing plants in the province, between 3,000 to 5,000 producing sour wells and about 1,000 kilometres of sour gas pipelines.

Since its enquiry into the sour gas well blowout near Lodgepole in late 1982, the ERCB has enforced a stricter regulatory regime for wells satisfying the definition of "critical sour well". On the first license application for a critical sour well made after the Lodgepole accident the ERCB held a hearing. This decision illustrates the extremely stringent conditions that will be imposed to protect public safety in connection with such wells. ${ }^{60}$

The Lodgepole blowout involved the blowout of a sour gas well resulting from deficient drilling practices. During the 67 days that the well was out of control, it deposited condensate on the immediately surrounding area seriously damaging soil and vegetation and emitted gaseous sulphur over an area of hundreds of thousands of square kilometres. Subsequently, an ERCB Inquiry Panel recommended

59: D.G. Beamer and E.R. Brushett "ERCB and Govemment Reaction to a Major Sour Gas Release".

60: Decision D 84-28, December 28, 1984. 
the establishment of a category of "critical sour wells" and specified special design measures to prevent blowouts and recommended the development of site-specific emergency response plans.

\section{Emergency Response Plans}

In 1976, the ERCB originally introduced the requirement for emergency response plans ("ERP's") for sour gas plants and associated facilities. ERP's are now required in a number of other circumstances:

(a) for the drilling of any sour gas well where there is any development within the emergency planning zone (a geographic zone defined by atmospheric dispersion modelling); (b) for the drilling and completion or servicing of a "critical sour well"; and (c) for pipelines and gathering systems where the $\mathrm{H}_{2} \mathrm{~S}$ content is one percent or more.

The operator of a sour gas facility will, in most cases, have both general and site-specific ERP's. In addition, the Government of Alberta has a general ERP for a sour gas release ${ }^{61}$ which was issued by the Minister of Alberta Public Safety Services under the authority of the Public Safety Services Act. Each local authority has its own ERP. The Government of Alberta ERP co-ordinates the action of the ERP's triggered on a release.

The basic contents of all ERP's are: definition of the stages of alert; responsibilities of all industry and government bodies; evacuation procedures; ignition procedures; contact information; maps; and residents' information.

\section{Alberta ERP}

The Alberta ERP describes the responsibilities of government departments and details various aspects of emergency procedures. The plan distinguishes between Category One and Category Two releases. A Category One release is one which occurs in a remote location with no people or livestock in the area and has a low release rate. A Category Two release is one which exceeds the Category One criteria.

Under a Category Two release, the full plan would be implemented. The operator would implement its own ERP and notify the ERCB. The ERCB would in turn notify the RCMP, other government departments, Alberta Environment and local authorities. The ERCB would establish two headquarters to manage the response. The first, an on-site command post would be established in conjunction with the operator to control the release and deal with other matters in the immediate area of the release. A main control headquarter would be established to deal with matters outside of the immediate area of release to provide support to the on-site post

61. "Govemment of Alberta Emergency Response Plan for a Sour Gas Release", January 20, 1988, Alberta Public Safety Services. 
and to provide an interface with the public, local authorities and government departments. ${ }^{62}$

\section{Evacuation and Ignition}

ERCB information letter IL 88-14 describes the ERCB's evacuation and ignition policy as it applies to sour wells during drilling, completion, servicing and production. Upon a release, members of the public within the immediate zone would be evacuated in accordance with the site-specific ERP. Evacuation outside that zone is to be handled in accordance with the Alberta ERP. Different levels of $\mathrm{H}_{2} \mathrm{~S}$ concentration trigger different responses. At an $\mathrm{H}_{2} \mathrm{~S}$ concentration of 20 $\mathrm{ppm}$, immediate evacuation of the public is required.

The information letter identifies two situations which require ignition: first, an uncontrolled release from wells that have a very high potential $\mathrm{H}_{2} \mathrm{~S}$ release rate and are located near population centers where evacuation would not be feasible, and second, if evacuation under an applicable ERP would not be practical for some unforeseen reason and public health and safety is at risk.

Sections 7.060 and 9.060 of the Oil and Gas Conservation Regulations and section 65 of the Pipeline Regulation set out additional emergency procedures requirements for sour gas processing plants, wells, and pipelines.

\section{RECLAMATION}

The Land Surface Conservation and Reclamation Act and the Regulated Oil and Gas Pipeline Surface Operation Regulations thereunder regulate the restoration of surface lands in Alberta, including lands disturbed by oil and gas operations. The Act applies to all land within Alberta except for land used for residential purposes. Agricultural land is subject to all provisions except the provisions of the Act requiring approval for regulated surface activities.

\section{Approvals}

Proper reclamation of land is achieved by requiring reclamation plan approval for major regulated surface disturbing operations prior to such operations commenc-

62. The functions of the Main Control Headquarters ("MCHQ") would include: providing support to the On-Site Command Post; compiling and evaluating air monitoring information; providing liaison, co-ordination and support for affected Local Municipalities; making evacuation and ignition decisions; providing information to the media and the public.

The functions of the On-Site Post would include: during the early stages of the release, monitor and redefine the hazard area until the MCHQ is established; control and supervise activities at the site to normalize the situation; wamings to, and evacuation of, residents within the area; ensure protection of life and property within the area; ensure the health and safety of workers at the gas release site; and provide situation reports to Main Control Headquarters. 
ing. ${ }^{63}$ These approvals are given by the Minister of Environment with the assistance of an inter-agency review committee consisting of officers from Alberta Environment, Alberta Forestry, Lands and Wildlife and affected municipalities. Presently, the only oil and gas industry-related operations that are regulated are oil and gas pipelines over a specified size threshold and major coal and oil sands projects.

Operators are required to submit plans of the proposed project showing how they intend to protect the environment and reclaim the land on the conclusion of operations. Once approval is obtained, operators are required to post a security deposit to guarantee that sufficient funds are available for the proper reclamation of the land. Development and reclamation approval is required prior to the abandonment of a regulated operation.

Non-designated operations such as well sites and small pipelines are not required to obtain approvals or provide security deposits but must still meet minimum reclamation guidelines prior to the issuance of a reclamation certificate. Specifically, where oil and gas operations involving seismic lines, well sites, production facilities or non-regulated pipelines are abandoned on public land, a reclamation certificate is required from Alberta Forestry, Lands and Wildlife. Where the operation is on other land, the certificate is issued by Alberta Energy.

\section{Operations}

During the term of the operations, field inspections by reclamation officers from the local area, the Departments of Energy, the Environment and Forestry, Lands and Wildlife ensure compliance with the terms of the approval. When operators do not meet reclamation standards, reclamation officers can order specified work to be done in order to comply with approval standards. If a reclamation order is not complied with, a stop order may be issued and the government may do the work itself and seek recompence from the operator. Operators must file periodic reports showing that reclamation obligations are being complied with.

Section 23 of the Act prohibits any person from commencing, continuing or recommencing any operation or activity in, or over the surface of any land without approval when the operation or activity is of a kind designated by the regulations as a "regulated surface operation". Under section 24, the Lieutenant Governor in Council is empowered to designate any kind of operation or activity as a regulated surface operation ("RSO') if the operation or activity is of a kind falling within a number of categories of operations.

63. Section 8 of the Land Surface Reclamation Act provides for Environmental Impact Assessments ("EIA's") for larger, more environmentally complex developments such as, for example, the Mackenzie Valley gas pipeline and the Alsands and Cold Lake oil sands megaprojects. ELA's are required for major commercial in situ oil sands plants, refineries, petrochemical plants, some gas plants and pipelines. In total, ninety-three environmentally complex projects have been submitted to Alberta Environment's EIA review process since the statute was enacted in 1974.

A new sour gas plant or a large sweet gas. plant (i.e., $56,000 \mathrm{~m}^{3}$ per day) may require an ELA. Recently, there has been some concem that Alberta Environment is now requiring an EIA in circumstances which clearly do not appear to fall within its own guidelines, for example, the recent application by Diamond Shamrock Exploration of Canada Lid. to drill a sour gas well near Pigeon Lake, Alberta (see Decision Report D87-3). Apart from the public controversy surrounding that particular application, there was nothing to distinguish it from numerous well licensing applications routinely processed by the ERCB. 
To date, only two types of oil and gas operations have been designated as RSO's: activities concerning pipelines and those conceming oil sands. Pursuant to the Regulated Oil \& Gas Pipeline Surface Operation Regulations, ${ }^{64}$ the "construction, operation, alteration, extension or abandonment of any pipeline" on any land in Alberta is designated to be an RSO. A pipeline is defined in the Pipeline Act, 1975, to be one that is $150 \mathrm{~mm}$ or more in diameter and $16 \mathrm{~km}$ or more in length. Pursuant to the Regulated Oil Sands Surface Operation Regulations, 65 “ "any exploration for oil sands and the opening up, operation, alteration, extension or abandonment of any oil sands site" on any land within Alberta is also designated to be an RSO.

\section{Development and Reclamation Approval Application}

Under section 24 of the Act, before an RSO can be commenced, continued or recommended, the person proposing such an operation must first obtain an approval. The application for an approval must be accompanied by plans and specifications prepared and submitted in compliance with the regulations. The application must also describe the nature of the surface disturbance that will result from the operations. The Minister of the Environment may require any additional information that he considers necessary. 
Each application must include a development plan and a reclamation plan. ${ }^{66} \mathrm{~A}$ development plan must include maps and plates that illustrate the development and reclamation proposal being submitted, and normally includes: maps indicating location of plants, areas of development, lease boundaries, roads and campsites; topographic maps showing details of permanent and temporary development, and location of disposal sites, spoil or discard piles, over-burden storage areas, roads,

66. In addition, the Regulated Surface Operations Regulations may require any or all of the following:

(i) a development report;

(ii) a surface disturbance report;

(iii) a geotechnical engineering report;

(iv) a surface water management report;

(v) a ground water management report;

(vi) a water quality management and pollution control report; and

(vii) an air quality management and pollution control report.

[s. 25-33 of 125/74]

The Development and Reclamation application in respect of pipeline operations must include:

(i) a development plan in part consisting of reports, maps, plans, sketches and other information prescribed under the Pipeline Act, 1975 and under Part 5 of the Land Conservation Regulations as well as a surface disturbance report;

(ii) a reclamation plan; and

(iii) in the case of a pipeline to be located within prescribed distances of waterbodies or watercourses:
(a) a development report;
(b) a surface disturbance report;
(c) a geotechnical engineering report;
(d) a surface water management report; and
(e) a groundwater management report.

The Development and Reclamation application in respect of oil sands operations must include:

(i) a development plan in part comprised of maps and plans or sketches as prescribed in Part 5 of the Land Conservation Regulations;

(ii) a reclamation plan;

(iii) a general descriptive outline of the proposed operation, including: the location, quality and quantity of the oil sands deposit to be developed; the planned rate of production; the term of the operation; the potential impact on the environment; and the economic feasibility of other types of operations;

(iv) a detailed description of: the procedures and equipment used to open up the oil sands site; the location of each processing plant; the procedures and equipment to be used in conveying raw materials from the oil sands site to each processing plant; the location and nature of any tailings and discard deposits resulting from processing; and the means of transporting synthetic crude oil and other products from each processing plant to the distribution transportation facility;

(v) a sequential schedule of all activities in opening up, operation, abandonment and reclamation, including the timing for each stage and the sequence of activities; and

(vi) insofar as may be applicable:

(a) a development report;

(b) a surface disturbance report;

(c) a geotechnical engineering report;

(d) a surface water management report;

(e) a groundwater management report;

(f) such other or further particulars as the Chairman in any particular case may request. 
residences, workshops, boundaries, pits, excavations, plants and cleared areas; aerial photographs to show the major areas of disturbance and development to be established and hydrologic diagrams showing drainage patterns and intended diversion schemes.

A reclamation plan normally consists of a schedule for reclamation, a summary of the physical and biological methods to be used in the reclamation and details of the subsequent use of the reclaimed site. Where the applicant proposes to create artificial water impoundments or leave open pits or excavations, the plan should include a long-term stability analysis of the foundations and a safety analysis of any open pit or other excavation. Where revegetation is practicable, the plan should include an analysis of the types of vegetation to be used and the means of establishing vegetation. Where reforestation is planned, an indication of the number and type of seedlings that will be required, the scheduling of reforestation and the subsequent nurturing program is necessary. The plan should also include a landscape illustration showing the final features after total reclamation.

When prescribed in the Regulated Surface Operations Regulations, a Development and Reclamation approval must be accompanied by a deposit to guarantee the proper performance of the operation and any reclamation in connection therewith. This deposit requirement is prescribed in the Regulated Surface Operations Regulations for both pipelines and oil sands.

\section{Standard of Reclamation}

The Lieutenant Governor in Council has the authority under section 38 of the Act to make regulations prescribing the manner and standard to which land must be conditioned, maintained or reclaimed. In the absence of such regulations, section 39 of the Act requires that the conditioning, maintenance and reclamation of the surface of the land must be performed in a manner satisfactory to the Land Conservation and Reclamation Council (the "Council").

The surface regulations governing pipelines and oil sands deal with the standard of reclamation by conditions attached to the terms of the approval. Nonregulated operations are the subject of a letter ${ }^{67}$ from the Chairman of the Council

67. The standards imposed pursuant to the letter are as follows:

1. All surface disturbances must be kept to a minimum, with appropriate measures taken to control wind and water erosion.

2. All trees must be salvaged or removed and disposed of by buming or other methods as approved by the Council.

3. Topsoil, including the surface organic horizon of the soil profile, should be selectively removed from the disturbed area and conserved for the reconstruction of the root zone.

4. All debris from the operator's equipment and facilities must be removed from the site and all solid materials must either be removed, or when necessary, buried with a minimum of 1.20 metres of soil cover.

5. The disturbed area must be recontoured to conform to the surnounding topography.

6. Topsoil and root zone material must be spread evenly over the entire area after it has sufficiently settled.

7. Areas where vegetation has been disturbed must be cultivated or conditioned to be compatible with adjacent or post-disturbance land uses.

8. On public lands the operator must attain a permanent maintenance-free plant cover that is compatible with vegetation on adjacent undisturbed lands.

9. Proper land management and reclamation, including erosion control and debris and waste disposal, must be conducted as the site operations progress. 
addressed to all operators and setting out minimum reclamation requirements for non-regulated operations. Specifically, the letter sets out the minimum requirements that the Council will apply in assessing whether the reclamation of lands has been satisfactory. In addition, any reclamation requirements embodied in the terms and conditions specified in Exploration Approvals, Development and Reclamation Approvals, or land surface dispositions and agreements will take precedence.

\section{Development and Reclamation Approval}

Development and Reclamation approval may be granted with or without conditions having regard to recommendations made by government agencies, any submissions received at a public meeting provided for under the Land Conservation Regulations if one is held by the Chairman, and the following factors:

(a) the general and overall impact of the proposed operation on the environment in relation to the Land Conservation Guidelines and the Development and Reclamation Guidelines prescribed in the applicable Regulated Surface Operations;

(b) the ability of the applicant to complete the proposed operation in a satisfactory manner and any reclamation required in connection therewith; and

(c) the past performance of the applicant in respect of any prior operations or reclamation conducted by him.

\section{Penalties and Enforcement}

The Act affords the Minister of the Environment general injunctive powers under reclamation orders and stop orders. As well, the Minister is authorized to remedy contraventions of the Act and breaches of the terms of any order, and to seek recompence from the person responsible. Fines are also available as an enforcement procedure.

Pursuant to section 9 of the Act, where the Minister is satisfied that any person has contravened the Act or failed to comply with an order or direction of the Council, the Minister may issue a stop order ${ }^{68}$ requiring the person to cease the contravention or stop operations, either permanently or for a specified period. Failure to comply with such an order is an offence and is subject to a maximum fine of $\$ 10,000$ for each day that the offence continues or a term of imprisonment of not more than 12 months, or both. In addition, the Minister may apply to the Court of Queen's Bench for an order requiring the person to comply with the stop order. Failure to obey the terms of the court order entitles an agent of the Minister to enter on any land and do any acts necessary to comply with the terms of the stop order.

68. Section 28 of the Act empowers the Minister to issue a special type of control order called a surface disturbance control order where a person carries on a regulated surface operation without approval or in contravention of the terms of the approval. The subsequent enforcement process is similar to that for normal control orders. 
Reclamation orders are provided for by sections 42 and $47^{69}$ of the Act. By order, the Council may direct the performance of any work necessary to prevent, contain, control, remove or remedy any contamination, degradation or deterioration of the surface of the land. A reclamation order must be directed to the operator concerned..$^{70}$ The Council is also empowered, under section 44 , to issue a reclamation order where a surface disturbance occurs on land outside the boundaries of the land held by the operator.

Section 18 of the Act provides for general penalties not exceeding $\$ 5,000$ and in default of payment, imprisonment of up to 3 months, for any person guilty of an offence under the Act or the regulations.

\section{CURRENT PROPOSALS FOR REFORM OF ALBERTA ENVIRONMENTAL LEGISLATION}

Oil and gas environmental law in Alberta is likely in the near future to change dramatically to incorporate a variety of features contained in the new generation of environmental laws in other jurisdictions including: strict liability, increased prosecutional emphasis, stiffer fines and directors' and officers' liability.

Impetus for changes in Alberta oil and gas environmental laws derives from a number of sources. In particular, the Review Panel on Environmental Law Enforcement has suggested major reform to Alberta's environmental laws generally in its report entitled an Action Plan for Environmental Law Enforcement in Alberta. Similarly, the federal department of Energy, Mines and Resources released its Commitment to the Environment Report in May, 1988.

In addition, there are a number of joint governmental and industry initiatives. For example, in the past year the ERCB has implemented a number of new regulations in consultation with the industry such as the recent Sulphur Recovery Guidelines, the Noise Suppression Guidelines, the new ERCB In Situ Oil Sands Operations, Vent Gas Handling, Air Quality and Land Disturbance Requirements,

69. Section 47 of the Act empowers the Council to hold an inquiry in respect of land that was previously held for purposes in connection with: the drilling, operation or abandonment of a well; the construction, operation or abandonment of a pipeline or battery; the conduct of exploration activities; and any operations designated as a regulated surface operation; where such land was surrendered to the Crown or the operation abandoned. The Council must make a report on the conclusion of the inquiry and make recommendations with respect to the work necessary to reclaim the land. If the identity of the operator of the land is known and the operator is still carrying on business in Alberta, a reclamation order directed to the operator or operators responsible for the surface disturbance may be issued. The order must be accompanied by an allocation of the expenses to complete the work between the Crown and the operator.

70. Under section 46, if a reclamation order is not complied with, the Chairman of the Council, with the written consent of the Minister, may cause work to be done to remedy the default, and the expense incurred must be paid by the Minister. These expenses constitute a debt payable to the Crown by the operator to whom the reclamation order was directed. An invoice for expenses incurred will be directed to the operator, and may be recovered either by legal proceedings or by a form of gamishee served on a party that purchases product from the operator.

The Crown can also ensure compliance with a reclamation order pursuant to section 33(2)(d). When a reclamation onder has been issued and the land has not been reclaimed in a satisfactory manner, the Minister may require that all or part of the security the operator has posted be retained until the work is completed and may, where he has expended money in respect of reclamation, order that the security be forfeited to the amount of the expenditure. 
the $\mathrm{NO}_{\mathrm{x}}$ Emission Control Policy, the Alberta Pipeline Construction and Reclamation Guidelines and the Water Recycling Guidelines for In Situ Oil Sands Facilities.

Examples of industry initiatives include the recent formation by the Canadian Petroleum Association ("CPA") of a Canadian Task Force on Oil Spill Preparedness to co-ordinate with a similar group sponsored by the American Petroleum Institute and the federal Review of Tanker Safety and Pollution Response Capability (the "Marine Spills Review") and the participation of the CPA and Independent Petroleum Association of Canada ('IPAC') in the joint task force to review ways to expedite the resolution of compensation claims arising from sour gas well blowouts.

\section{A. REPORT OF THE REVIEW PANEL ON ENVIRONMENTAL LAW ENFORCEMENT}

In 1987, Alberta's Environment Minister appointed a six member review panel to investigate the enforcement of environmental laws in the Province of Alberta. The review was motivated in large part by the government's embarrassment resulting from its inability to prosecute Western Co-operative Fertilizers Ltd. of Calgary under the Clean Air Act following its release of a toxic sulphur trioxide cloud over Calgary in early 1987. A waiver provision in the company's operating license provided that air quality standards specified in the license did not apply to start-up operations and procedures.

The Review Panel released its final report on January 12, 1988. The report is now being reviewed within Alberta Environment and implementation of its recommendations is under consideration.

The following is a summary of the report's major proposals and recommendations:

(1) Development of a comprehensive list of priority substances and establishment of a formal policy with respect to the development of emission control requirements and ambient air quality standards.

(2) Repeal of the existing ambient air quality standards contained in Part I of the Clean Air (Maximum Levels) Regulations. In the view of the Review Panel, the existing regulations are not enforceable because of the difficulty in proving the source of an emission where the contravention is the cumulative effect of a number of sources of emission, and because there are no offence provisions with respect to the existing regulations. In substitution, the Review Panel proposes publication of a comprehensive set of objectives for a number of specific contaminants incorporating an airshed management concept, which specifically recognizes areas requiring enhanced protection (e.g. urban areas) and areas of industrial or other emissions.

(3) Establishment of water quality objectives through a basin planning approach which integrates water allocation objectives as well as fisheries, general environmental and long-term water use requirements.

(4) Licenses should contain specific performance standards applicable to normal operations and based on past performance in the industry, available technology, established standards for the industry and also maximum emission 
limits based on levels that could give rise to an immediate danger to human health, life, property or the environment and which would apply during commissioning and planned start-up/shut-down operations.

(5) The practice of including waivers in legislation or licenses exempting licensees from operating limits and standards during start-up and shut-down situations would be abolished. For example, section 10(2) of the Clean Air (Maximum Levels) Regulations would be repealed. Alberta Environment would have the option of issuing a short-term, interim operating license for the commissioning period.

(6) Emphasis would be placed on negotiating more realistic license emission limits and then strictly enforcing compliance. At present, limits are frequently set unrealistically high and then regarded as performance objectives rather than as requirements.

(7) The public would be notified of all license applications and issuances and a summary of license terms would be published. A formal license appeal process to a new Environment Statutes Appeal Board would be established, with appeal to the courts only on questions of law or jurisdiction.

(8) As part of each license application, the applicant would be required to include a declaration regarding start-up/shut-down sequence and timing, and conduct a worse case assessment for upset situations, including a comprehensive response plan. This would require amendment of section $8(2)$ (b) of the Clean Air Regulations, section 5(3) of the Clean Water (Industrial Plants) Regulations and section 8(2) of the Clean Water (Municipal Plants) Regulations.

(9) Licensees would continue to monitor emissions for informational purposes. Measured values in excess of limits would not be contraventions but could lead to a specific review of the operator's source standards and compliance record and would be deemed accurate and admissible as proof of a contravention of emission limits. Contravention reports would be required to contain more detailed explanations of the cause and effect of the contravention.

(10) The Review Panel has suggested the implementation of a new enforcement model focusing on a uniform, predictable and automatic enforcement response in the event of a breach of a license limit. For example, control orders would be issued in all cases of deviation from a performance limit, without the need for approval by senior management of the enforcement unit. The control order provisions in section (13)(1)(a)(v) of the Clean Air Act and section 14(1)(a)(iv) of the Clean Water Act would be amended to include reference to contaminants that adversely affect the environment.

(11) The power to issue stop orders and cease construction orders would be formally delegated outside the Minister's office to a senior official of the enforcement unit. Stop orders would be routinely issued in all circumstances where a maximum limit is exceeded and prosecution initiated provided that there is sufficient legally admissible evidence available. The stop order provisions in section 14(1)(c) of the Clean Air Act and section 15(1)(c) of the Clean Water Act would be amended to include those situations that pose an immediate danger to the environment. As under current law, failure to comply with a control order or a stop order would result in court proceedings to enforce 
the order. Consent of the Attorney General under section 17(9) of the Clean Water Act would no longer be required to initiate a charge.

(12) Existing provisions providing for appeal of control orders and stop orders would be repealed. This would include the Stop Order Appeal Regulation under the Department of Environment Act. Directives would only be used to require that information be submitted.

(13) Legislation would be amended to allow a new type of order to suspend unregulated operations releasing air contaminants that are likely to be harmful to public health or the environment.

(14) The following offences would be considered as absolute liability offences: failure to obtain a permit or license, failure to report a spill, submitting false information, failure to take immediate emergency measures in event of a spill, and failure to comply with a control order or a stop order.

(15) Environment enforcement staff would be designated as special constables authorized to issue tickets pursuant to the Violation Ticket Regulation under the Summary Convictions Act for minor noise, odor and dust contraventions.

(16) Fines would be increased in line with other jurisdictions, with each day constituting a separate offence. Statutory amendments would permit orders stripping financial gains achieved by polluting, requiring that specific action be taken to remedy a situation, that security be posted to ensure compliance with an order or ordering that an offender perform community service.

(17) Environmental statutes would be amended to specifically state that directors, officers or employees could be personally liable for flagrant violations in which they have a clear and direct involvement.

A number of industry associations have established the Alberta Industry Environmental Council to monitor and liaise with Alberta Environment with respect to regulatory changes resulting from the Report of the Review Panel. If the proposals of the Review Panel result in legislative amendments to the Clean Air and Clean Water Acts, similar changes in the ERCB's mode of administering Alberta's oil and gas industry-specific environmental laws will be inevitable. It is not conceivable within the Alberta regulatory framework for the ERCB to regulate the oil and gas industry under an enforcement approach radically inconsistent with that employed by Alberta Environment in administering the umbrella statutes.

Already, there are some signs that Alberta Environment is beginning to implement the proposals on a piecemeal basis. For example, stricter emission standards are being set in licenses. Start-up and shut-down waivers are no longer being included in licenses. Alberta Environment is requiring more detailed information on plant operations and the approval process is being extended as a result of increased public participation.

\section{B. THE JOINT TASK FORCE ON SOUR GAS WELL BLOWOUT COMPENSATION}

The final report of the Joint Task Force on Sour Gas Well Blowout Compensation is expected in the near future. The task force, consisting of representatives of the ERCB, the CPA, IPAC, the Pembina Institute for Appropriate Development (PIAD) and the Pembina Agricultural Protection Association, was formed last year 
at the request of PIAD, a group formed after the Lodgepole sour gas well blowout in 1982. The mandate of the group is to develop industry guidelines to deal with blowout compensation issues.

The task force has defined three categories of costs associated with sour gas well blowouts: (i) Tier one costs, which have been defined as up-front "out-of-pocket" costs incurred immediately after a blowout such as the costs of relocation, hotels and lodging and stock transportation and feeding; (ii) Tier two or on-going costs, which are clearly identifiable in the short term after the event such as damage to paint on houses, equipment corrosion, sick or dying cattle and damage to standing crops; and (iii) Tier three costs associated with longer term affects such as soil degradation, reduction in the growth rates or fertility of livestock or a drop in milk production in dairy cattle.

Tier one costs would be reimbursed or paid directly on an immediate basis, Tier two costs, when costs are identified and substantiated, and Tier three costs would be subject to settlement by one of four methods after appropriate identification of the degree of damage. The four possible methods of settlement would include: negotiation, mediation, arbitration and the courts.

\section{RECENT LEGISLATIVE INITIATIVES}

\section{A. INTRODUCTION}

Developments in other jurisdictions such as the federal Canadian Environmental Protection Act ("CEPA"), Ontario's Environmental Protection Act and the U.S. Comprehensive Environmental Response, Compensation and Liability Act of 1980 are representative of the tougher environmental legislation likely to be implemented in Alberta.

\section{B. CANADIAN ENVIRONMENTAL PROTECTION ACT}

CEPA is, in part, a consolidation of a number of pre-existing federal environmental statutes such as the Canada Water Act, the federal Clean Air Act and the Environmental Contaminants Act. CEPA's most important new initiatives are provisions which permit the Department to impose "cradle-to-grave" regulation of scheduled toxic substances, the movement towards rigorous enforcement, the enactment of stiffer penalties, liability for clean-up costs, and director and officer liability.

CEPA reflects the federal government's broad constitutional authority to legislate environmental matters under its constitutional powers relating to sea coast and inland fisheries, trade and commerce, and "peace, order and good government" ("POGG"). In its recent decision in $R$. v. Crown Zellerbach Canada Limited," the Supreme Court of Canada held that the federal government could use its POGG power to legislate in respect of marine pollution. LeDain J. in his reasons stated that: (at p. 432 and p. 436)

For a matter to qualify as a matter of national concem . . . , it must have a singleness, distinctiveness and indivisibility that clearly distinguishes it from matters of provincial concem and a scale of impact on provincial jurisdiction that is reconcilable with the fundamental distribution of legislative power under 
the Constitution . . . Marine pollution because of its predominantly extra-provincial as well as international character and implications, is clearly a matter of concem to Canada as a whole.

The drafters of CEPA clearly intend to rely on the POGG power as a constitutional basis for the legislation, stating in the preface to the statute that "the presence of toxic substances in the environment is a matter of national concern" and that toxic substances "cannot always be contained within geographic boundaries". The Crown Zellerbach decision indicates that the Supreme Court may be supportive of an expanded role of the federal government in the protection of the environment.

In order to ensure a more effective federal/provincial co-ordination of environmental law enforcement, and presumably to reduce the risk of constitutional challenge, sections 34(6) and 98 of CEPA allow for the negotiation of federalprovincial agreements on the administration of the Act. Where the federal government and a province agree in writing that provincial legislation ensures an equivalent level of protection, the federal government will exempt the province from the application of the federal regulations. Presumably, an equivalent level of protection is provided if: quality standards are equivalent; measurement and test procedures are comparable; penalties are comparable; and citizens' rights to request investigations are comparable.

Part II of the Act deals with regulation of toxic substances. A substance is defined by section 11 as toxic if:

it is entering or may enter the environment in a quantity or concentration or under conditions . . . having or that may have an immediate or long term harmful effect on the environment . . . or that may constitute a danger to human life or health.

Before a substance can be regulated as "toxic", the substance must be identified, sampled and assessed. If it meets the definition, it must then be added to the Toxic Substances List before it may be regulated under the Act. Examples of currentlylisted substances include PCB's and Benzene.

Once on the list, the federal government can control the substance in question through regulation, guidelines and codes of practice dealing with handling and disposal as well as by an outright ban of the substance.

Pursuant to regulations under CEPA, the locations of toxic substances must be reported. Initially, the CPA expressed concern that the reporting requirements relating to the CEPA Domestic Substances List would, in effect, require the oil and gas industry to report locations of each and every wellhead and as well to identify locations of various naturally occurring gases and oils. In response to this concern, however, Environment Canada adopted, as an administrative position, the requirement that all wells be reported only under a generic heading of "Oil/Natural Gas Wells" and not by specific locations.

In addition, the oil and gas industry is required to report additives used to enhance recovery which are manufactured or imported by the company but is not required to report with respect to such additives at the time they are extracted with natural substances emanating from a well. This is consistent with the substance criteria on incidental reaction product and section 26(3)(d) of CEPA. However, where additives are used for purposes of effecting specific chemical modification of oil or natural gas in situ, rather than enhanced extraction or recovery, the resulting synthetic material would be a reportable substance.

Section 13 of CEPA requires the Minister to compile a Priority Substance List of substances that most urgently need to be assessed for their environmental and 
health impacts. As these substances are assessed, more will be added to the substances already on the Toxic Substance List.

There are currently 50 substances on the Priority Substances List for assessment of risks to health and environment. These include single substances (e.g., benzene), classes of substances (e.g., polynuclear aromatic hydrocarbons, chlorinated methanes) and mixtures of substances which originate from a specified source, process or activity (e.g., nitrogen oxides from combustion processes, used crankcase oils and bleach-plant effluent from kraft and sulphite mills).

In addition several substances have already been assessed as toxic and are subject to controls as set out in various international agreements to which Canada is a signatory. These include sulphur dioxide $\left(\mathrm{SO}_{2}\right)$, nitrogen oxides $\left(\mathrm{NO}_{x}\right)$ and halons.

There are four categories of enforcement activities available to the regulators under CEPA: inspection, investigation, enforcement without resort to court action, and enforcement through court action.

\section{Inspection}

Section 100 of CEPA allows an investigator to conduct an inspection to ensure compliance with the CEPA. The investigator may examine substances, products or containers; take samples of the items he inspects; and examine books and records and take copies of them.

Section 100 requires the investigator to obtain a search warrant prior to entering a private dwelling place, unless the occupant consents to the entry. Where there are exigent circumstances involving danger to the environment or human life or the potential loss of evidence, the investigator can act without a warrant. Investigators are also given powers of seizure and detention which may only be exercised in the circumstances set out in section 104.

The Enforcement and Compliance Policy published by the Department indicates that a program of inspections will be used to verify compliance with CEPA. The frequency of inspection will be a function of the potential risk of the substance in question and the past compliance record of the company.

\section{Investigations}

Under section 108 of CEPA, two or more individuals may, by petition alleging that an offence has been committed, require the Minister to investigate the alleged offence. On receipt of such an application the Minister is obliged to investigate and report to the petitioners within 90 days on the action the Minister proposes to take.

\section{Without Resort to Court Action}

Examples include directives from officers, tickets and Ministerial orders.

\section{Court Action}

The Enforcement Policy requires that contraventions of CEPA that result in injury to any person or serious risk to the environment be prosecuted through the 
court system. The same is the case where a specific government directive is ignored or an inspector is interfered with in the course of his duties.

The penalties that are provided for by CEPA are summarized in the following table:

\section{PENALTIES UNDER CEPA}

\section{SECTION OF CEPA}

s.111

s. 112

s.113

s.114

s.115(1)

s.115(2)

s.115(2)

s. 116

s. 129

s. 133

s.118

\section{Obstruction of inspector and} failure to assist

Fail to inform or test as required

Most substantive provisions (e.g. failure to give info. to Minister, manufacture or importation in contravention, failure to comply with ministerial orders, etc.)

Knowingly provide false or misleading info. on new substances, toxics

Intentionally or recklessly causing a disaster or wanton or reckless disregard for lives or safety

\section{Causing death}

Causing bodily harm

Any other offences not specified above

Profits earned through violation

Failure to comply with court order issued under CEPA

Each day that offence continues is separate violation

MAXIMUM

(SUMMARY

CONVICTION)

MAXIMUM

(INDICTMENT)

$\$ 200 \mathrm{~K}$ and/or

6 months jail

$\$ 200 \mathrm{~K}$ and/or

6 months jail

$\$ 300 \mathrm{~K}$ and/or

6 months jail

$\$ 300 \mathrm{~K}$ and $/$ or 6 months jail

N/A

N/A

N/A

$\$ 200 \mathrm{~K}$ and/or

6 months jail

Fine equal to profits

$\$ 200 \mathrm{~K}$ and/or

6 months jail

Penalty depends
N/A

N/A

$\$ 1$ million and/or 3 years jail

$\$ 1$ million and/or 5 years jail

\section{Unlimited fine and/or \\ 5 years jail}

Life (Cr. Code)

10 years

(Cr. Code)

N/A

N/A

$\$ 1$ million and/or 3 years jail

$\$ 1$ million and/or 3 years jail

In addition, a court may, under section 130, order any of the following:

(a) an injunction prohibiting activity that may result in another offence;

(b) directing correction of harm done by an offender;

(c) directing notification by the offender to those affected of the facts of the offence;

(d) directing publication of facts of the offence by the offender;

(e) performance of a community service related to the offence, e.g. mitigation, restoration, rehabilitation; and 
(f) directing financial compensation of the Minister for costs of preventative or corrective measures

Among the most important provisions in CEPA are those dealing with liability of directors, officers and agents. Section 122 provides as follows:

Where a corporation commits an offence under this Act, any officer, director or agent of the corporation who directed, authorized, assented to, acquiesced in or participated in the commission of the offence is a party to and guilty of the offence, and is liable to the punishment provided for the offence, whether or not the corporation has been prosecuted or convicted.

Under section 36, a person who owns a toxic substance which is released into the environment or a person who contributes to the cause of such release is obliged to:

(a) report the spill;

(b) take all reasonable emergency measures to ensure public safety; and

(c) make reasonable efforts to notify the public of the situation.

If the federal government is required to do the actual clean up, under section 39 it can recover the costs from the owner of the substance or from any person whose negligence contributed to the situation. Strict liability is imposed on the owner whereas fault must be established to collect from others.

\section{Likely Federal Initiatives}

In the future, the federal government is likely to intervene to an increasing extent in situations where it does not view the province as enforcing equivalent environmental protection. Under the decision of the Supreme Court of Canada in the Crown Zellerbach case, it is clear that the federal government has broad constitutional authority under the POGG power to regulate environmental matters.

Two examples of possible federal initiatives are the following. Environment Canada is currently particularly concerned with the extent of nitrogen oxides emitted by vehicles, industrial engine compressor stations, and other internal combustion engines burning fossil fuels. Ottawa is in the process of phasing in more stringent regulations to reduce such emissions by $30 \%$ in the next five years. This is a matter currently dealt with by the ERCB pursuant to its new emission control policy for compression facilities.

Second, the federal government is committed pursuant to an international protocol to reduce sulphur dioxide emissions by $30 \%$ by 1993 . Again, if Alberta, through policies such as the ERCB's recent sulphur recovery guidelines, is not successful in achieving the federal standard, one might expect increased federal regulation through the addition of $\mathrm{SO}_{2}$ to the Priority Substances List under CEPA.

Specifically, under CEPA a province will be exempted from national requirements imposed federally only if the province implements and enforces equivalent regulations pursuant to CEPA's Enforcement and Compliance Policy. Equivalency requires: equal control, comparable compliance measurement techniques, comparable penalties, comparable enforcement policies and procedures, and comparable rights of individuals to request investigations and have access to findings. 


\section{Imposing the Federal Environmental Assessment and Review Process on Provincial Projects}

Beyond CEPA, it is clear that the federal government has broad constitutional authority to subject provincial energy and resource projects to the federal Environmental Assessment and Review Process. Moreover, the decision of the Federal Court of Canada in April, 1989 in the case of the Canadian Wildlife Federation v. Minister of Environment ${ }^{2}$ indicates that environmental groups may seek mandamus orders requiring the federal Minister to subject provincial projects to federal environmental review.

Quite apart from the outcome, the case is interesting since it illustrates the breadth of the federal power to review provincial projects. The case involved a review of the federal environmental review of projects to construct the Rafferty and Alameda Dams on the Souris River in Saskatchewan. The claim to federal jurisdiction over the environmental review process rested on six grounds:

(i) Under the International River Improvements Act, the Souris River is an international river and the Act requires a federal licence to construct an improvement on an international river.

(ii) The federal Environmental Assessment and Review Process Guidelines, which are embodied in an order of the Governor-General in Council, are by their terms applicable to "proposals undertaken by federal agencies, funded by the federal government, located on federal land or having an environmental effect on an area of federal responsibility". In the case of the Souris River Project, the flood plain included about 4,000 acres of land owned by the federal government.

(iii) The Souris River flows into North Dakota and under the Boundary Waters Treaty, the federal government is obliged to prevent pollution of waters flowing across the Canada/U.S. Boundary.

(iv) The federal Navigable Waters Protection Act requires a Transport Canada licence for projects in navigable rivers.

(v) The federal Migratory Birds Conservation Act requires Environment Canada to seek assurance that no net loss in waterfowl production will occur as a result of the project.

(vi) The federal Fisheries Act gives the federal government authority over fish habitats.

In short, federal involvement in the provincial environmental review process was required to ensure that the inter-provincial environmental impact of the project on Manitoba and the international impact on North Dakota and on other areas of federal responsibility such as Indian lands, federal lands, migratory birds, fisheries and navigable rivers were given due consideration.

Based on this reasoning it is clear that the federal government has the constitutional authority under a number of heads of power to intervene in the environmental review of provincial resource projects such as the OSLO oil sands project, the

72. Canadian Wildlife Federation Inc. v. Canada (Minister of the Environment), [1989] F.C.J. No. 225 Action No. T-80-89. 
Oldman River Dam ${ }^{73}$ and the Alberta Pacific Pulp Mill and it is not clear that the province would have strong constitutional grounds on which to object now that the federal-provincial agreement that gave Alberta sole responsibility for environmental assessments on projects that fall chiefly within provincial jurisdiction has expired.

\section{COMPREHENSIVE ENVIRONMENTAL RESPONSE, COMPENSATION AND LIABILITY ACT OF 1980}

The Comprehensive Environmental Response, Compensation and Liability Act of 1980 ("CERCLA") makes certain specific categories of persons jointly and severally liable for the cost of cleaning up contaminated real property, i.e. removing hazardous substances from the property and either treating the substance on site or disposing of the removed material in an approved manner. Persons caught by CERCLA include any person with a current ownership interest in or who exercises any control over the facility, or any person who owned or operated the facility at any time there was a disposal or release of a hazardous substance. This means, for example, that a person who owns or owned contaminated property can be liable simply because leaking, leaching or seepage occurs during the term of ownership.

There are three major defenses to liability under CERCLA. First, section 101(1) provides a defense for "acts of God"' defined as "an unanticipated grave natural disaster or other natural phenomenon of an exceptional, inevitable, and irresistible character, the effects of which could not have been prevented or avoided by the exercise of due care or foresight". Second, section 107(b)(3) provides a thirdparty defence when: (i) the act of the third party was the sole cause; (ii) the third party is not related to the owner or operator in any way; and (iii) the owner exercised due diligence to prevent the release.

Finally, section 4(3)(b)(i) of the Superfund Amendments and Realization Act of 1986 adds an innocent purchaser defence for any purchaser who establishes by a preponderance of evidence that at the time of purchase he had no reason to know that a hazardous substance existed on the site. The defence is available only where the purchaser has exercised due diligence by means of all appropriate inquiry and has nevertheless failed to detect the presence of the contamination.

\section{RECENT ALBERTA LEGISLATION}

To some extent Alberta has already moved to tougher legislation in the areas of hazardous waste storage and transportation of hazardous goods.

\section{Transportation of Dangerous Goods}

The Transportation of Dangerous Goods Act proclaimed into force in 1985 regulates any company that transports any dangerous goods including, for example, crude oil, condensate and various poisonous, corrosive, flammable or radioactive

73. But see Friends of the Oldman River Society v. Canada (Minister of Transport), [1989] F.C.J. No. 904 Action No. T-865-89. The court distinguished Canadian Wildlife on the grounds that in that case there was direct involvement of a federal minister who was statutorily obligated to deal with environmental considerations and the Guidelines Orders. This was not so in Friends of the Oldman. 
substances used in the exploration, development and production of oil, gas, gas liquids, sulphur and heavy oil.

Section 23 of the Act provides that "any officer, director or agent of [a corporation which commits an offence and] who directed, authorized, assented to, acquiesced in or participated in the commission of the offence is a party and guilty of the offence, ... . whether or not the corporation has been prosecuted or convicted."

The following are some other significant features of the legislation:

(1) Transportation through pipelines is exempt.

(2) Each company is responsible for both itself and its agents.

(3) Each project transported must be properly classified, documented, labelled and placarded.

(4) Each company is responsible for developing response plans, reporting accidents and training and certifying employees originating, receiving or transporting dangerous goods.

(5) Penalties are stringent with prosecution by way of summary conviction or indictment, fines of up to $\$ 100,000$ and imprisonment for up to 2 years.

\section{Hazardous Chemicals}

As of April 1, 1988, Alberta has toughened its Hazardous Waste Regulations under the Hazardous Chemicals Act. ${ }^{74}$

(1) Hazardous wastes must be disposed of at the new Swan Hills disposal facility within 1 year of being generated.

(2) Only 10 tonnes of such waste may be stored at any time.

(3) All spills must be reported immediately.

(4) Penalties for non-compliance include up to 90 days in jail and fines up to $\$ 25,000$.

Currently, section 2(f) of the Hazardous Waste Regulations under the Hazardous Chemicals Act exempts a long list of oil and gas industry wastes from the requirements of the legislation including "drilling fluids, produced waters, oily waste, fracture fluids, reformates, completion fluids, process and run-off waters, spent iron sponge or similar sweeteners and waste treater hay resulting from the exploration, development or production of crude oil or natural gas" approved pursuant to the Oil and Gas Conservation Act, the Oil Sands Conservation Act or the Pipeline Act.

\section{ENVIRONMENTAL CONSIDERATIONS IN THE DRAFTING OF OPERATING AGREEMENTS}

\section{A. INTRODUCTION}

Where an operator is responsible for the operation of an environmentally sensitive type of facility or a facility located in an environmentally sensitive area of the province, special attention should be paid to the drafting of provisions of the

74. R.S.A. 1980 , c. H-3. 
operating agreement dealing with cleanup, surrender and abandonment of the site, cost allocation, insurance and indemnities. In many circumstances where environmental issues are of particular concern, the standard provisions of the 1981 Canadian Association of Petroleum Landmen Operating Procedure (the "Operating Procedure') or of typical Construction, Ownership and Operation agreements may not be entirely suitable. Provisions sinilar to those contained in the CAPL 1988 Model Frontier Joint Operating Procedure (the "Frontier Operating Procedure") may be more appropriate and their adoption should be considered.

\section{B. ABANDONMENT PROVISIONS}

In several respects, the standard provisions of the Operating Procedure governing abandonment are deficient in circumstances where environmental issues make abandonment a matter of particular concern to the parties.

\section{1981 CAPL Abandonment Provisions}

The abandonment procedure is set out in Article XII of the Operating Procedure. A party proposing abandonment serves the appropriate notice and, if all concur, the abandonment is for the joint account. Parties who do not concur in the proposal to abandon may either elect to take over the well or are assigned the other parties' interests "without consideration or warranty" and must pay the other parties their share of the salvage value of existing materials and equipment. Subsequently, when the well is no longer maintained as a producing well, the interests are re-assigned to the original owners; however, the responsibility for well abandonment remains with the parties that took over the well.

There are corresponding provisions dealing with the abandonment of wells drilled pursuant to independent operations which ensure that, as between the parties, the responsibility for abandonment is borne by the joint operators participating in the independent operations.

The allocation of costs for abandonment of wells which are not completed is dealt with by the inclusion of such costs in the definition of "drilling costs". Drilling costs, in the case of a well which is not completed for the taking of production, include "the costs of abandoning the well pursuant to the regulations and costs of restoring the drilling site".

\section{Drilling Costs}

Two concerns arise from the definition of "drilling costs" used in the Operating Procedure.

Firstly, the definition of "drilling costs" includes only costs of abandoning the well pursuant to the Regulations, as defined. If, because of unusual circumstances, the abandonment procedure varies from that prescribed by the Regulations, such costs are arguably not included.

Secondly, the definition of "drilling costs" includes costs associated with abandonment of uncompleted wells but does not include other costs associated with environmental protection such as those included in Clause 216 of the standard form PASWC 1983 Accounting Procedure (the "Accounting Procedure") which 
provides that expenses chargeable by the operator to the joint account include the cost of "requirements, whether statutory or otherwise, relating to the ecology or environment of the Joint Property"'. The Accounting Procedure goes on to provide that costs of related studies will be subject to the approval of the parties.

\section{AFE Procedure}

Where costs of abandonment are expected to exceed $\$ 25,000$, the Operating Procedure contemplates that the operator will send out an Authority for Expenditure ("AFE") but the agreement does not specify what happens if one of the parties refuses to execute the AFE. More generally, the AFE mechanism may be inappropriate to costs such as those associated with abandonment and site restoration, which may be mandatory rather than elective.

If the standardized AFE procedure is retained in drafting a customized operating procedure, then it may be appropriate to deem parties who refuse, without reasonable cause, to execute the AFE, to have executed the applicable AFE. In addition, in certain circumstances it may be prudent to have joint operators provide operators with security for reclamation costs in much the same way as the government in certain circumstances now requires the operator or licensee to provide a bond or other form of security.

\section{Standard of Care}

Another matter which may require further clarification in a customized operating procedure is the standard to which the operator may be held in its abandonment procedure. On the one hand, the Operating Procedure specifies that abandonment is to be done in accordance with the Regulations. On the other hand, the overall standard of care imposed by Section 304 of the Operating Procedure on the operator in its conduct of all operations is that it be conducted in a good and workmanlike manner and in accordance with good oilfield practices. Since compliance with a statutory standard of conduct is generally evidence that one has not been negligent, if the operator complies with the standard set by the Regulations, it should avoid tortious liability. However, it does not necessarily follow that, in exceptional circumstances, such compliance will satisfy the operator's obligation under Section 304 of the Operating Procedure.

The standard by which the operator will be held accountable should be clarified. Either compliance with the Regulations should be deemed satisfaction of the obligations under Section 304 or the Operating Procedure should specify that compliance with the Regulations only sets the minimum requirement, in which case the drilling costs definition should be amended to include all abandonment costs (not only those in accordance with the Regulations).

\section{Re-Assignment}

The last aspect of the abandonment provisions which should be re-evaluated in drafting an operating procedure for use in a situation in which environmental issues are of particular concern is that relating to the re-assignment of interests. As the Operating Procedure is currently drafted, with the exception of title preser- 
vation wells, when, as a consequence of one joint operator's unwillingness to participate in an operation, there is an assignment of an interest, there is provision for the re-assignment of the interest in the relevant zone upon the happening of certain events. The Operating Procedure stipulates that notwithstanding the re-assignment, the responsibility for abandonment remains with the parties that were originally assigned the interest. However, vis-à-vis third parties, the owner of the re-assigned lands may by responsible for abandonment and reclamation. For example, a holder of a re-assigned interest may be held responsible to the lessor for site clean up. In particular circumstances, this potential source of liability should be considered and, if necessary, addressed.

\section{Frontier Abandonment Provisions}

The Frontier Operating Procedure alleviates many of the problems associated with the Operating Procedure provisions relating to abandonment by the inclusion of the following definitions:

\footnotetext{
"Abandonment" means the proper plugging and abandonment of a well in compliance with the Regulations [definition provided below], including the salvage of the salvageable material and equipment respecting such well and the restoration of the well-site.

"Regulations" means all statutes, laws, rules, orders and regulations in effect from time to time and made by govemments or governmental boards or agencies having jurisdiction over the Agreement Lands or over the operations to be conducted thereon.
}

By the inclusion of a definition of abandonment, the standard of every abandonment is addressed. Each abandonment must meet a double-barrelled standard: the abandonment must be proper, and in compliance with the Regulations. Proper abandonment may entail a procedure which exceeds the standard set by the Regulations. The joint operators are liable for their proportionate share of the costs associated with the proper abandonment. There is no scope for argument that their liability is limited to only those costs associated with compliance with the standard set by the Regulations. Unlike the Operating Procedure, the potential for conflict between the general standard of care imposed on the operator and the specific standard imposed with respect to its conduct of abandonment is avoided by the imposition of the double-barrelled test.

Moreover, since the definition includes well-site restoration, it is clear that under the Frontier Operating Procedure obligations relating to well-site restoration are part of the joint obligations of all parties. The definition of well costs in the Frontier Operating Procedure includes not only those costs associated with abandonment but also many other costs associated with reclamation and environmental studies and thereby ensures that these additional costs are accounted for.

Subclause 9.08(G)(a) of the Frontier Operating Procedure deals with the problem of allocation of well costs where participation in various operations has differed. Specific mention is made of abandonment costs:

the costs of the logging and Abandonment of such well shall be allocated to the respective portions of such well in the ratio that the meterage of a portion of such well bears to the total depth of such well.

The above provision for allocation of costs associated with well abandonment is subject to the general provisions in subclause $9.08(\mathrm{G})$ which provide for equitable allocation by agreement, and failing agreement, by arbitration.

The problem created by the unsuitability of dealing with the mandatory costs associated with abandonment by the use of the AFE procedure is also avoided under 
the Frontier Operating Procedure. Under subclause 6.01(B)(b)(iii) of the Frontier Operating Procedure, the operator may charge the Joint Account (without AFE) costs or expenses arising when the "Operator is required to conduct an operation respecting the Agreement Lands by the Regulations, where failure to conduct such operation should be inconsistent with good oil field practice or could result in the prosecution of the Operator thereunder, in which case the Operator shall conduct such operation for the Joint Account, unless the Parties make arrangements whereby such operation shall be conducted other than for the Joint Account".

\section{TERMINATION OF THE OPERATING PROCEDURE}

The termination provision in Article XXVIII of the Operating Procedure is inadequate. Pursuant to this provision, the Operating Procedure terminates when all documents of title have terminated, all wells have been abandoned and a final settlement of accounts has been made among the parties. Unfortunately contingent tortious and statutory liabilities may continue after such events.

By way of illustration, consider the following situation. The well is abandoned and the Operating Procedure terminates. (In fact, according to its terms the Operating Procedure terminates upon abandonment even if the abandonment is not done in accordance with the Regulations.) The well is on land in respect of which the operator holds the surface lease. The surface restoration was inadequate and, consequently, the surface owner suffers damages for which he sues the operator. In addition, the regulatory authorities intervene imposing additional cleanup obligations. In such a scenario, the operator's contractual right to indemnification from the joint operators may no longer exist since the Operating Procedure has terminated.

To rectify this potential problem, the termination provision of the Operating Procedure should include a survival clause preserving the operator's right to contribution and indemnification from the joint operators where liabilities contingent at the time of termination of the Operating Procedure become actual liabilities. 
In the Frontier Operating Procedure, this issue is addressed by clause 23.11 which deals with the term of the agreement and stipulates that indemnities are to survive. It reads: ${ }^{75}$

... all Documents of Title have terminated and all wells on the Agreement Lands have been Abandoned, all equipment relating thereto has been salvaged and a final settlement of accounts has been made among the Parties provided that those provisions related to audit, liability, indemnity, disposal and salvage of material and enforcement on default shall survive for six (6) years thereafter.

\section{REPLACEMENT OF OPERATORS}

Under the Operating Procedure, upon replacement of an operator the replaced operator is released and discharged of its duties and obligations and the successor operator assumes all duties and obligations of the operator except the unsatisfied duties and obligations of the operator accrued prior to the effective date of the change of the operator. Accordingly, the replaced operator remains liable for the unsatisfied duties and obligations accrued prior to the effective date of the change of operator.

With respect to tortious liability in particular, it may be years before the contingent liability materializes and becomes an actual liability. Since at the date of change of operatorship the liability has not accrued, the replaced operator may be relieved of such liability even in circumstances where the liability is as a result of the replaced operator's gross negligence. Under the terms of the Operating Procedure, the obligation to satisfy those claims which have not accrued as of the effective date are assumed by the new operator; however, if they arise because of the gross negligence of the replaced operator, the joint operators may object to any indemnification because of the exclusion for gross negligence. Similarly, any insurance that may otherwise have covered the situation may not be available because of an exclusion for gross negligence.

75. Theoretically, in circumstances where the operator does not have a contractual right to seek indemnification or contribution from the joint operators, it may be left to rely on a right to partition and accounting. Article XV of the Operating Procedure establishes that the joint operators are tenants in common. Under the law of tenants in common, if one tenant unilaterally makes an improvement to the common property, the other tenant cannot restrain the first tenant from proceeding with the improvement, but the first tenant has no right to recover a share of the costs of the improvement from the second tenant. Nonetheless, the second tenant may enjoy the benefits of the improvement made by and at the sole expense of the first tenant; that is, the second tenant is entitled to its proportionate share of the profits from the common property.

At common law (which is essentially restated in Alberta's Law of Property Act), the first tenant's only remedy in the face of such inequity, is to apply to the court for a judicial partition and/or sale of the common property and for an accounting between the parties. The application for an accounting must be incidental to an application for partition and/or sale and not otherwise. Since, in rendering the accounting order, the court will take into consideration the expenditures made at the expense of the first tenant, that tenant will, in this fashion, be compensated for its expenditures at the time of the order, assuming that the property has value at the time.

Similarly, if an operator inadvertently makes capital expenditures which it is not entitled to recover under the Operating Procedure, then, again presuming the property has value at that time, the operator may recover the expenditures upon sale of the property. However, expenditures relating to well abandonment and site restoration are typically made at a time when the property has no residual value and therefore the operator's right as a tenant in common may be ineffectual.

Moreover, since pursuant to Article XXIII of the Operating Procedure the parties are prohibited from exercising any right to apply for any partition of the joint lands or sale thereof in lieu of partition, the operator may be prevented from exercising the primary rights arising from its status as a tenant in common. However, to the extent that provisions in Article XXIII purport to oust the court's jurisdiction, the provisions may not be enforceable. 
To rectify this problem, an appropriately worded exclusion to the replaced operator's release should be inserted in the Operating Procedure.

\section{E. INSURANCE}

The dollar amounts of coverage required by Section 311 of the Operating Procedure with alternative (A) are too low in circumstances where there are unusual dangers involved in operations because of the existence of toxic substances, or because operations are being conducted in environmentally sensitive areas. In addition to the insurance coverage mandated by Section 311 of the Operating Procedure, many prudent operators now also carry umbrella liability insurance which covers bodily injury, death and property damage to a limit of \$10-15 million and "well control" to a limit of \$5-10 million.

Generally, coverage for long term environmental damage and sudden and accidental spills is excluded from comprehensive general liability policies and environmental impairment liability insurance is difficult to obtain. There are, however, a few underwriters writing this insurance on a claims-made basis (i.e., the claim must be made during the policy period). Generally, the coverage limits are low (\$1-2 million both per claim and annual aggregate). Minimum deductibles of $\$ 10-50,000$ are not unusual. Typically, all insured locations must be scheduled and cleanup costs are often not covered. Usually, claims are excluded from coverage where the insured knew about or could reasonably have foreseen the environmental impairment prior to the inception of the policy or where the environmental impairment is attributable to the insured's intentional, wilful or deliberate non-compliance with applicable statutes and regulations. Also, payment of fines and penalties is often not covered.

Operators and joint operators may also want to reconsider the Operating Procedure requirements relating to insurance coverage of contractors and subcontractors. Under the Operating Procedure, the only obligation of the operator with respect to contractors or subcontractors is to use reasonable effort to ensure that the contractor or subcontractor carries adequate insurance. What happens if the operator uses reasonable effort but the contractor nonetheless does not carry adequate insurance? Both under tort law and under many applicable statutes, the operators and joint operators may be liable for damages caused by contractors and subcontractors. Moreover, if the operator and joint operators have assumed that the contractors and subcontractors are carrying adequate insurance, then they themselves may not have procured the amount of insurance which they would have otherwise.

Similarly, under some of the insurance provisions now used, the joint operators are responsible for carrying their own insurance but may not have the right to be informed of whether the other joint operators are carrying adequate insurance. Given the frequency of joint and several liability, the inadequacy of one joint operator's insurance may negatively impact on the other joint operators.

\section{F. INDEMNIFICATION}

Pursuant to the indemnification provisions of Section 402 of the Operating Procedure, operators are entitled to indemnification for operations carried on pursuant to the Operating Procedure provided that they have not been grossly negligent. 
Difficulties may arise in situations where an operation is not carried out strictly pursuant to the Operating Procedure because of some irregularity in procedure. In addition, and perhaps more importantly, there is a lack of judicial interpretation of the term gross negligence in the area of oil and gas operations and it is extremely difficult to know where the line will be drawn between gross negligence and negligence.

The Frontier Operating Procedure recognizes the difficulty surrounding the interpretation of gross negligence and addresses it by the inclusion of the following definition:

"Gross Negligence" means such wilful misconduct or such wilful omissions or such wanton and reckless conduct or omissions, as constitutes in effect a wilful or utter disregard for harmful, foreseeable and avoidable consequences.

\section{G. SURRENDER AND QUIT CLAIM OF JOINT LANDS}

Article XI of the Operating Procedure provides for the surrender and quit claim of a party's interest to the other parties. It appears that in drafting the surrender provision the liabilities which were foremost in the drafters' minds were those that related to rentals, and, accordingly, the provision deals adequately with such liabilities by providing that surrender may only occur if "there is not then existing with respect to those joint lands an obligation which cannot be avoided by surrender or quit claim to the grantor of the title documents".

The provision is silent, however, on the matter of contingent liabilities. Parties may surrender interests in the joint lands in respect of which there are contingent but not existing liabilities, and thereby shift the ultimate burden for liabilities relating to environmental matters. Accordingly, if contingent liabilities are a concern, the responsibility for them should be addressed in the surrender provisions.

As a practical matter, in circumstances where there are legitimate concerns about contingent liabilities, when a party receives a surrender notice it should consider whether it appears that the surrendering party is trying to avoid liabilities other than those associated with the payment of rentals. If there is reason to suspect that there are other contingent liabilities, then the recipient of the surrender notice may consider doing likewise.

Under the Frontier Operating Procedure, liability for the Abandonment (which by definition includes site restoration) cannot be shifted by surrender. Prior to surrender, the salvage value of the surrendering party's interest is estimated, as is its share of abandonment costs, and the payment by the appropriate party is required.

\section{H. CONCERNS RELATING TO FACILITIES}

\section{Facilities Not Covered By Operating Procedure}

The Operating Procedure governs only operations on the joint lands such as the drilling of wells, and not the ownership and operation of joint facilities constructed or operated in connection with the joint lands. Specifically, the definition of "equipping costs" establishes the extent to which downstream operations are covered by the Operating Procedure; i.e., it includes initial treatment costs, but specifically excludes costs incurred beyond the point of entry into a gathering system, plant 
or common facility. A separate construction, ownership and operation agreement covering these facilities should be executed by the owners, however, persons frequently neglect to enter into such agreements erroneously believing that the Operating Procedure extends to all related facilities.

In instances where there is no agreement governing the operation of a facility and an operator finds itself liable for either environmental damage associated with the operation of a facility or reclamation costs associated with a facility site, the operator will not have the benefit of a contractual right of indemnification and contribution from the other joint venture participants. To guard against such an eventuality operators should ensure that there are subsisting agreements governing the operation of all facilities used by the joint venture participants.

\section{Assignments of Interests}

In drafting operating agreements governing facilities, drafters are confronted with many of the same issues as are encountered in the drafting of agreements relating to well operations. A general discussion of the specific provisions of agreements for the construction, ownership and operation of facilities is outside the scope of this paper, with the exception of the issue of assignability of interests. In our discussion of abandonment of wells, we indicated that interest owners should be aware that other owners may use surrender of interest as a method of avoiding reclamation liability. The other obvious method which interest owners should guard against is the use of assignment.

For example, once a well has been depleted past a certain point, the administrative costs associated with the well may make it uneconomic for a major company to retain its interest; however, a junior company, with lower overhead expenses, may find continued operation of the property economic, provided that it can purchase the property for an attractive price. With the expectation of avoiding abandonment costs, the major company may be willing to sell the property at an extremely low price. Until recently, whether or not the junior company which purchased the property conducted the abandonment and site reclamation in accordance with the applicable government regulations, the company which sold was relieved of liability for these operations. In the future this may not be the case. Many new-generation environmental statutes expressly fix liability on prior owners, thus, in the future assignment may not relieve past owners of obligations relating to environmental damage. Moreover, it appears that as a matter of policy the Energy Resource Conservation Board is now pursuing past owners of "orphaned" wells.

An analogous problem is occurring, and may be expected to occur with increasing frequency, with respect to facilities. Under typical construction, ownership and operation agreements, an owner may avoid obligations for site reclamation by simply transferring its interest to another entity. Under most of these agreements, the transfer is effective upon the assignee executing a copy of the construction, ownership and operation agreement; the other owners of the facilities do not have even a right to withhold consent provided that the requisite documentation has been executed. When it is time to conduct the reclamation operations, those other owners may find that their proportionate costs are increased because prior owners have assigned their interests to either financially distressed entities or shell companies. 
This potential problem should be addressed in the drafting of these agreements by:

(a) either requiring bonds or other forms or security, or requiring the establishment of a reserve fund from which the costs of reclamation may be paid;

(b) providing that interest owners have the right to withhold consent to the assignment by another interest owner based on an assessment of the financial capabilities of the proposed assignee; or

(c) providing that notwithstanding any assignment, assignors are not relieved of their obligations under the agreement.

\section{STRUCTURING A SALE OF OIL AND GAS ASSETS TO PROTECT AGAINST ENVIRONMENTAL LIABILITIES}

\section{A. INTRODUCTION}

Significant environmental risks may be associated with particular oil and gas including wells and batteries situated in environmentally sensitive areas, sour gas plants, processing facilities, storage facilities and refineries. These liabilities may be statutorily imposed on current or past owners or users who have generated, deposited, stored, spilled or disposed of pollutants or contaminants, or may derive from common law rights of action such as nuisance, negligence, trespass, riparian rights, or Rylands v. Fletcher-type strict liability. For example, purchasers of properties with environmental problems may render themselves liable to prosecutions, administrative orders and clean up orders by environmental regulators as well as to potential civil claims for environmental damage or personal injury.

This portion of the paper outlines methods of structuring a sale of environmentally sensitive oil and gas assets to protect the vendor or the purchaser, as the case may be, of such assets from such liabilities. In particular, it focuses on due diligence disclosure and risk allocation issues which arise in the drafting of a sale and purchase agreement pertaining to such assets.

\section{B. DISCLOSURE}

Where a vendor is aware of environmental concerns associated with an asset about to be conveyed to a purchaser, the vendor should disclose fully the nature and extent of the problem to the prospective purchaser. Disclosure creates a "volenti" defence to any subsequent action by the purchaser. Moreover, if a latent defect is hidden from the purchaser the likelihood of the vendor being sued for fraudulent misrepresentation or deceit action is increased. In addition, the failure of consideration doctrine may apply to negate the transaction even where there has been innocent non-disclosure.

If the purchaser, based on the vendor's disclosures, is willing to accept the environmental risk such that the purchase is in effect on an "as is" basis, the vendor 
should include an express acknowledgement and a broad indemnity clause in the formal documentation. ${ }^{76}$

\section{DUE DILIGENCE}

A diligent purchaser will generally insist on the right to some form of environmental inspection or audit of the properties prior to closing and will contract for the necessary rights of access. In some instances, the purchaser will expressly seek a right to make soil, groundwater and other environmental tests or the contract may provide that the parties will commission the appropriate professional expert to conduct an environmental audit. In addition to physical inspection of the property, the cautious purchaser may also want to have the seller agree to complete an environmental questionnaire detailing its operations and past and present use of hazardous substances as well as to conduct interviews with current and former employees and

76. The following are sample purchaser acknowledgement and vendor indemnification clauses:

The purchaser acknowledges that the Property has been used as a plant for the manufacture and storage of refined oil products and that such use may have resulted in the existence or leakage of toxic, hazardous, dangerous or potentially dangerous substances into the soil or the structures located on the Property. The vendor makes no representations or warranties whatsoever regarding the fitness of the Property for any particular use or regarding the presence or absence on the Property or any surrounding or neighbouring lands of or the leakage or emission from or onto the Property of any toxic, hazardous, dangerous, or potentially dangerous substance or condition, including, without limitation any asbestos, gasoline or heavy metals.

The purchaser will satisfy itself as to the condition of the Property and the fitness for its intended use. If the purchaser does not elect to terminate the Agreement during the inspection period provided for herein, the purchaser shall be deemed to have accepted the condition of the Property and the existence of any toxic, hazardous, dangerous, or potentially dangerous substances or conditions thereon or the leakage or emission thereof from or onto the Property, and will be solely responsible for any work desirable or necessary or ordered by reason thereof, and all liabilities, claims, demands, and obligations arising therefrom of any such substances from the Property.

The purchaser shall indemnify and hold harmless the vendor from and against any claims, demands, liabilities, losses, damages and expenses suffered by the vendor arising out of or in connection with any and all such environmental liabilities relating to the Property from and after the Closing Date. If the purchaser elects to terminate the Agreement during the Approval Period, the vendor's obligations under the Agreement shall be at an end and the purchaser shall not be entitled to make any claim for damages arising out of any breach of any warranty contained herein or for any costs or expenses incurred by it in connection with the identification of the Property, the entering into of the Agreement or in connection with any inspections or investigations carried out by the purchaser in connection with the Property. 
adjacent landowners. The purchaser will generally want full access to all permits and licenses and all environmental studies. ${ }^{77}$

Where the parties agree to an environmental audit, the sale agreement must specify who selects the auditor and who pays the cost, the time frame in which the audit must be completed, the standards the auditor is to use in determining whether remedial work is required (e.g. legislative requirements or industry guidelines) and the extent of access the auditor will have for inspections and physical testing. The extent of the auditor's access to the vendor's records, employees and government officials is often a point of serious negotiation.

Environmental audits for facilities should include some or all of the following:

(a) visual inspection of the inside and outside of the facility;

(b) review of the chain of title and governmental records to determine prior owners and their use of the facility;

(c) review of processes where hazardous substances may have been employed;

(d) examination of governmental and company records of the facility's operations;

(e) interviews with past and present operators of the facility;

(f) analysis of soil samples;

(g) an investigation of underground tanks; and

(h) ground water and air sampling.

77. An example of a clause providing for an environmental audit by the purchaser is as follows:

Prior to the Closing, the vendor shall have provided the purchaser with access, during reasonable business hours and on reasonable prior notice, to the properties for the purpose of conducting an environmental assessment of the properties and all permits related thereto, provided that such assessment is conducted after prior arrangement with the vendor and in a manner which will not interfere with the vendor's operations. Such environmental assessment shall be at the purchaser's sole expense.

In the event that the environmental assessment conducted by the purchaser indicates the previous and/or on-going release of hazardous substances at or under the site ("Adverse Environmental Conditions"), then:

(i) if the parties agree upon the nature and extent of the remediation of the Adverse Environmental Conditions, the vendor may elect to commence, and subsequently continue, remediation measures in which event the Closing shall take place, with such remediation to be completed as promptly as practicable after the Closing; or

(ii) if the parties hereto are unable to agree upon the nature and extent of such remedial measures or if the vendor shall elect not to commence agreed-upon remediation actions, the purchaser may (A) terminate this Agreement without liability to the vendor, or (B) consummate the transactions contemplated by this Agreement and accept the Properties with knowledge of such conditions.

The parties agree that any determination as to the nature and extent of remediation of the Adverse Environmental Conditions shall include a method, standard or other criteria for establishing when remediation shall be deemed complete for purposes of this Agreement. The parties agree that the remediation work, as well as the method, standard or other criteria for deeming it complete, shall comply with the application or relevant and appropriate requirements of all federal, provincial, municipal or local laws. In the event the parties are unable to agree as to the method, standard or other criteria for deeming the remediation complete, the purchaser and the vendor each shall select an environmental consultant who in tum shall select a third consultant to review all relevant technical data and information. The consultants shall make a determination, which determination shall be fully and finally binding between the parties, as to the method, standard or other criteria for deeming the remediation complete. The environmental arbitrator shall have no authority to determine contractual issues that may affect both parties and nothing in this Section is intended to confer such authority. 
Where the purchaser has a right of inspection, the vendor should limit the purchaser's rights of access to ensure that the purchaser's inspections do not interfere with the vendor's operations and should require that properties be restored to their pre-existing state after testing.

The purchaser may also desire to discuss the vendor's compliance with environmental standards with the relevant statutory authorities. ${ }^{78}$ In some circumstances, the vendor may be concerned that such enquiries may draw the attention of government authorities to problems which may otherwise have gone unnoticed.

The information generated by an environmental audit can be damaging to a vendor in the event that the sale does not proceed to closing and, therefore, all efforts should be made to maintain its confidentiality. The contract should impose upon the purchaser confidentiality obligations.

Also, in some circumstances it may be possible to structure a solicitor/client privilege defence to disclosure of the environmental reports (which would normally be discoverable documents). If the privilege defence is to be erected and preserved, the environmental investigations must be conducted in the proper fashion from the outset. The basic requirements are as follows:

(a) The report must be prepared in connection with a request for legal advice relating to compliance with environmental laws and such request should be documented by written communication between the vendor and its solicitor.

(b) The report must be maintained confidential both in the course of its preparation and after. The report should be marked private and confidential and circulation should be restricted strictly to those with a need to know.

(c) Outside consultants should be hired as agents of the solicitor.

(d) The solicitor should deliver an opinion on compliance with environmental law based on the report.

Some vendors carry out regular environmental audits of their environmentally sensitive assets on an ongoing basis. As part of the audit, operational performance of major projects is compared with pre-determined environmental management objectives or standards. Informational support in this area is being provided by the Canadian Petroleum Association, which is currently working towards the development of environmental auditing guidelines to achieve the performance levels established by the Association's Environmental Code of Practice.

\section{PUBLIC SEARCHES}

The standard set of pre-closing searches may reveal to a prospective purchaser potential environmental concerns and particular attention should be paid to the results of these searches when the purchaser suspects environmental problems. For example, action searches conducted at the court houses of the relevant jurisdictions may disclose third party claims for environmental damage. Similarly, searches

78. An example of the type of clause a purchaser may request is the following:

The vendor hereby authorizes and directs all agencies, departments or other relevant authorities to release any and all information in their possession respecting the Properties to the purchaser, and further hereby authorizes each of them to carry out inspections of the Properties upon the request of the purchaser. The vendor agrees to execute any specific authorization pursuant to this paragraph. 
of title at the Land Titles Offices may reveal lis pendens in respect of same. The freehold title searches may also reveal agreements entered into by the Department of the Environment pursuant to section 7 of the Land Surface Conservation and Reclamation Act restricting the use of the lands. If a governmental agency has conducted clean up activities necessitated by the vendor's operations and has not recovered its costs, a writ of execution may be filed at the appropriate Sheriff's Office.

When acting for purchasers of environmentally sensitive assets, there are a number of additional searches at public offices in Alberta available to obtain information relating to environmental matters. These searches will give the prospective purchaser an indication of whether the vendor is subject to any outstanding obligations under provincial environmental legislation and highlight potential environmental problems relating to the subject lands and facilities.

For example, if the purchaser believes that the land has at any time been subject to reclamation obligations under the Land Surface Conservation and Reclamation $A c t$, a search can be done to ensure such obligations have been satisfied. The Land Conservation and Reclamation Council (the "Council") will indicate on request whether the land is subject to a reclamation obligation or not, and will, if required, provide a copy of the Reclamation Certificate if one has been issued. If there are outstanding reclamation obligations, the search response will indicate that a Reclamation Certificate has not been issued because of outstanding reclamation deficiencies. The particulars of these deficiencies may be obtained with the permission of the owner or operator. The Council deals with all lands other than Crown lands, which information can be obtained from Alberta Energy.

A second set of searches can be done through Alberta Environment. Alberta Environment will issue a letter dealing mainly with environmental enforcement procedures, that is, infractions which have resulted in the department taking steps to compel compliance. The search request must include the location of the property and the names of the owners dating back to 1971, the year that Alberta Energy first began keeping such records.

The Alberta Environment search will disclose whether any stop or control order has been issued against the owner or operator of the land under the Clean Water Act, the Clean Air Act or the Hazardous Chemicals Act. If there has been any such order, the search response will indicate the date, the company against which it was issued, the land involved and the nature of the order. If the search discloses violations or orders, the purchaser will have to follow-up with the present or past owner to determine how the order or violation was dealt with and whether there are any outstanding concerns.

Also, the Director of Standards and Approvals maintains a record of licensed facilities and violations of the licenses, particularly those under the Clean Water Act and the Clean Air Act. A search with the Director will disclose whether the facilities in question are licensed under the relevant Act and whether there have been specific violations of the terms and conditions of the licence. Supplemental searches can be done on stack emissions data, water discharge data and ambient monitoring information.

A copy of all information supplied to the person requesting it will be forwarded to the company that operates the facility, although the searcher's name will be kept confidential. 


\section{E. REMEDIES}

The purchase and sale agreement should specify the purchaser's remedy in the event that the due diligence process reveals environmental problems. The suitability of any particular remedy will depend, in part, upon the precision with which the environmental liability can be assessed and quantified. Depending upon the circumstances, for example, an agreement may provide that the purchaser has an option to elect between two remedies, or that one remedy shall apply to liabilities of a certain type or below a certain monetary threshold and a different remedy shall apply to liabilities of a different type or in excess of the established monetary threshold. ${ }^{79}$

\section{Termination/Rescission}

If a satisfactory environmental audit is made a condition precedent to closing the transaction the purchaser will have the right to refuse to complete the purchase if the audit discloses unforeseen environmental liability.

Theoretically, upon execution of the purchase and sale agreement the purchaser obtains an equitable interest in the subject property. If the transaction is not completed, the equitable interest reverts to the vendor. For those of the view that ownership of any interest in a property with environmental problems is to be assiduously guarded against, the remedy of rescission $a b$ initio may be preferable to termination. If regulatory agencies start to zealously search out and pursue owners and former owners (as reported in some American jurisdictions), a preference for rescission over termination may develop.

\section{Remedy or Price Reduction}

If the extent and cost of the environmental liability associated with the property can be precisely quantified, it may be satisfactory to provide that the vendor shall either remedy the problem to the purchaser's satisfaction prior to closing or reduce the purchase price by the cost of the remedial work required..$^{80}$ Unless this remedy is used in conjunction with another remedy (e.g. indemnity), the purchaser assumes the risk that the environmental problem is greater than the parties believed at the time of closing.

\section{Exclusion of Problem Property}

If the transaction encompasses several properties and the environmental problem is associated with a specific property, it may be possible to exclude the contentious

79. An important source for this segment of the paper was "Due Diligence in Modem Mining Deals: How to Protect your Client from Buying a Pig in a Poke' by Dean R. Massey in 33 Rocky Mt. Min. L. Inst. 2-1 (1987) and for further discussion of this topic, the reader is referred to that article.

80. An example of a vendor's covenant to perform remedial work is as follows:

The vendor shall proceed, at its cost, to perform, or cause to be performed, the Remedial Work. To the extent the Remedial Work must be performed after the closing, the purchaser shall grant the vendor and its contractors and consultants access to the property without cost in order to perform such work. The purchaser may from time to time provide the vendor with proposed schedules of development of the Property, and the vendor shall use reasonable efforts to perform the Remedial Work so as not to interfere with such schedules. 
property from the transaction, reduce the purchase price accordingly, and proceed with the sale.

\section{Contingency Fund}

A reserve fund for the benefit of the purchaser may be established by the vendor to be drawn against by the purchaser in the event that the potential liability materializes. The reserve may be an actual trust or escrow account or it may be in the form of a letter of credit or other security instrument. This mechanism is suitable if the purchaser is only concerned with incurring environmental liability within a finite period of time.

\section{Payment From Income}

If the purchase price is either to be paid in installments or to include an earnout component, or the transaction is structured such that the vendor retains an interest in the property (e.g. overriding royalty), the agreement may provide that damages suffered by the purchaser as a result of the specified environmental problem will be set off against the installments, profits or income, as the case may be, otherwise owed to the vendor.

\section{Risk Allocation/Indemnity}

Every agreement will either expressly or impliedly allocate risks between the parties. The parties may agree not only on who will bear what risk but also on the quantity of the risk to be borne by the party and an indemnity from the other party for any liability in excess of that party's allocation. As with all indemnities the effectiveness of this remedy is dependent upon the continued existence and solvency of the party providing the indemnity.

\section{Insurance}

Current comprehensive general liability insurance excludes most forms of environmental damage, however, older forms of policies did not contain the same extensive exclusions and may continue to provide coverage for incidents which occurred during the term of the policy notwithstanding that the injury was discovered after the term expired.

As a part of the due diligence process a prospective purchaser should review the insurance policies of the vendor, and if there is any possibility that any of the old policies may apply to future claims, the purchaser should ensure that access to the policies is preserved and that a procedure is implemented whereby the purchaser can avail itself of the coverage extended by the vendor's old policy.

As a practical matter this is usually achieved by covenants from the vendor to pursue any claims against its insurers and to serve timely notices under such insurance policies combined with an indemnity from the vendor for any losses or damages suffered by the purchaser as a result of occurrences which arose prior to the effective date of the sale. The indemnity is important because, without it, after the sale the vendor may not suffer any insurable loss. 


\section{F. REPRESENTATIONS AND WARRANTIES}

Oil and gas purchase and sale agreements typically contain heavily negotiated representations and warranties such as the standard representation to the effect that the vendor has acquired all necessary licenses, permits and other authorizations and has operated the properties in accordance with good oilfield practices and in full compliance with all statutes, regulations, rules, orders and directives of all governmental agencies, departments and other authorities.

Given the nature of the existing Alberta statutory framework of environmental regulation, a vendor should be extremely cautious in giving such broad performance representations and should endeavour to negotiate a limitation in the scope of such representations. In particular, terms and conditions in operating licenses often include performance standards or emission limits which are regarded by the regulatory authority and the licensee more as performance objectives than as strict standards. In this circumstance, the licensee may be technically in breach of the licence provisions even though the applicable regulatory authority is not requiring strict performance of the licence requirements. Often, breaches of environmental standards are not enforced until a specific complaint is received. Fines are sufficiently small and infrequent that they are sometimes treated as a cost of doing business. Consequently, at any point in time a vendor may be responsible for minor violations or contraventions of a number of environmental statutes, and it is often not possible for a vendor conducting extensive operations in the province to give the broad representation of compliance, particularly where there may be third party operators on many of the properties.

From a vendor's perspective, there are many methods of limiting the scope of representations and warranties. The vendor may insist that representations as to the performance of all obligations under leases relate to the petroleum and natural gas leases only and do not extend to surface leases. Further, the no default under or violation of laws representation should have a substantial compliance or materiality limitation and should relate to the petroleum and natural gas rights only. By these means the vendor escapes warranting that there has been no violation of laws relating to surface or general environmental laws. Similarly, in the provision regarding the interim compliance with laws (i.e., the representation that during the period between entering into the purchase and sale agreement and the closing of the transaction contemplated by the purchase and sale agreement the vendor has complied with all applicable laws), there should be a materiality limitation and a restriction to petroleum and natural gas rights related laws.

Representations relating to the obtainment and status of all permits or licenses should be limited to material licenses. It is preferable from the vendor's point of view to merely represent that it holds all licenses and not that they are in good standing or that there has been no default under them. If pressed, the vendor should make sure that the representation is limited by materiality and also ensure that the representation relates only to licenses relating to the petroleum and natural gas rights and not the tangibles and surface rights.

One of the more specific representations frequently requested by purchasers is to the effect that all wells have been abandoned and shut-in in accordance with good oil and gas field practices and in compliance with applicable laws. From the vendor's perspective, it is preferable not to give such a representation. Particularly 
where the vendor has not been the operator of the properties, the relevant information may not be within the vendor's knowledge. Again, if the vendor is forced to give this representation, it should try to limit it to either one standard or the other, that is, either in accordance with applicable laws or industry standards.

In general, a sophisticated buyer in a good bargaining position will seek a wide range of environmental representations and warranties concerning the property including the following:

(a) possession of all required environmental permits;

(b) compliance with all environmental laws and permits;

(c) no notice of any violation of any law or permit has been received and there is no basis for assertion of any such violation;

(d) no lawsuit, claim or proceeding has been asserted or commenced and there is no basis for such assertion;

(e) all required notices under applicable environmental laws have been filed, including notices relating to releases of hazardous substances;

(f) absence of any required material expenditure needed to comply with environmental laws;

(g) absence of any condition which if known to governmental authorities, would give rise to a claim of violation of law or permits, or require a material expenditure to comply; and

(h) absence of toxic substances and underground storage tanks or a commitment to remedial action if such items create a problem.

The vendor for its part will want to limit potential liability under these representations, and generally will attempt to do so by employing one or more of the following techniques:

(a) including a time limit on the survival of representations and warranties;

(b) setting a floor on claims to avoid having to deal with less significant problems;

(c) limiting damages for all breaches of warranties or specified warranties to the purchase price or a specified portion thereof;

(d) limiting its liability to the cost of the actual remedial work needed to correct the environmental problem and expressly excluding responsibility for lost profits, decline in market value of the prospects, internuption of business operations and any other type of special, incidental, consequential or exemplary damages;

(e) excluding liability for fines and penalties, legal and consulting costs and third party claims;

(f) limiting liability to contamination arising during its ownership of the property; and

(g) limiting its liability to problems of which it had knowledge at the time of the disposition.

Where the purchaser has conducted extensive due diligence investigations the vendor may seek to reduce the extent of its representations on that account. The purchaser, on the other hand, will want the representations and warranties to continue unabated notwithstanding its investigations. 
As indicated above, from the vendor's perspective the extent of liability for any breach of warranty should be limited by the amount paid for the particular asset affected. If there is a breach of a representation relating to a tangible and the portion of the purchase price allocated to the tangible is low as is typically the case, then the liability for the breach of the warranty would be capped by that low allocation.

Generally, as a matter of drafting style it is better to rely on broadly drafted representations and warranties so as to avoid the implication that arises with respect to more narrowly drafted representations that matters not expressly covered by the specific and narrow representations have been expressly and purposefully omitted. Accordingly, in usual circumstances the purchaser will attempt to force the vendor into giving broad representations. However, in some circumstances, the parties may prefer express and extensive customized environmental warranties. ${ }^{81}$

81. A simple example of a customized representation which takes into account environmental considerations is as follows:

The Property contains no contaminant (as that term is defined in the Environmental Protection Act, R.S.O. 1980, c. 141, as amended) deposited, added, emitted or discharged by the vendor, its officers, directors, agents and employees but not including its tenants during the period that the vendor has owned the Property.

A more complex example is as follows:

(i) The vendor has been and is in substantial compliance with all laws, regulations and orders relating to the environment. Further, the vendor has received no written notice of non-compliance, and does not know, or does not have reasonable grounds to know, of any facts which could give rise to a notice of non-compliance, with any such laws, regulations, or orders.

(ii) The vendor has obtained all permits, licenses and approvals which are required for the operation of its business as presently being conducted and all such permits are valid and in full force and effect and no violations thereof have been experienced, noted, or recorded, and no proceeding is pending or, to the best of the vendor's knowledge after due inquiry and investigation, threatened to revoke or limit any of them.

(iii) The vendor has not used any of its facilities, or permitted them to be used, to generate, manufacture, refine, treat, transport, store, handle, dispose, transfer, produce or process any contaminants, dangerous substances, pollutants, hazardous wastes or hazardous materials, except in substantial compliance with all laws, regulations, or orders.

(iv) The vendor has never been convicted of an offence for non-compliance with any laws, regulations, or orders or been fined or otherwise sentenced or settled such prosecution short of conviction.

(v) The vendor has never defaulted in reporting to the proper governmental authority on the happening of a substantial occurrence requiring it by law, regulation, or order to do so.

(vi) The vendor has disclosed all such reporting to the purchaser and provided full details.

(vii) The vendor has not caused or permitted, and has no knowledge of, the Release of any hazardous substances on or off-site of its property or of any release from a facility owned or operated by third parties, but with respect to which the vendor is alleged to have liability. All wastes and other materials and substances disposed of, treated or stored on or off-site of real property owned or occupied by the vendor, whether hazardous or non-hazardous, have been disposed of, treated and stored in substantial compliance with all laws, regulations and onders. To the best of the vendor's knowledge after due inquiry and investigation, Schedule " $A$ " identifies all of the locations where hazardous substances and any other environmental contaminants used in whole or in part by the vendor or resulting from the vendor's businesses have been or are being stored or disposed of. 


\section{G. ADJUSTMENT AND INDEMNITY CLAUSES}

Indemnification and adjustment provisions are useful where there are potentially large environmental risks and liabilities to allocate among the vendor and purchaser. The recipient of the indemnity should ensure that the indemnification specifically extends to both direct damages and indirect damages, that is, third party claims.

A concerned purchaser will want to negotiate a covenant making the vendor liable after closing for the cleanup of environmental problems and indemnifying the purchaser from any loss occasioned from such problems. The indemnity may be general, indemnifying the buyer, its officers, directors and employees, from any claims, liabilities, damages, losses or expenses arising out of the breach by the vendor of any representation or warranty. ${ }^{2}$ Alternatively, the indemnity may be specifically tailored to address environmental issues. Typically, the buyer will want to have the indemnity include the costs of environmental consultants and engineers, witness fees and legal fees.

A vendor may negotiate the period of time for which it may be liable under the indemnity to the purchaser, and the extent of indemnification may again be limited to the amount of the purchase price attributed to the relevant asset. The extent of indemnification may also be limited by a general form of limitation. For example, it may be limited to losses in respect of petroleum and natural gas rights based on the premise that it was only these rights which were attributed significant value. A vendor may also try and limit the indemnification to damages which have actually accrued prior to the effective time. This is an attempt to cut off liability for contingent liabilities, that is, liabilities that have not accrued prior to the effective time.

A purchaser may have difficulty collecting on indemnification for those problems of which it had knowledge prior to closing. Ideally, a vendor should stipulate that it will not assume any liability for indemnification in circumstances where the purchaser had knowledge prior to closing of the subject matter giving rise to the incurred liability.

Notwithstanding any successful efforts by the vendor to limit its indemnity, its third party liability may not be limited to the negotiated amounts. Applicable

82. A typical clause providing for post-closing remedial work and indemnity is as follows:

After the closing, the vendor covenants at its sole cost and expense, to remove or take remedial action with regard to any materials released to the environment at, on or near the property prior to the closing for which any removal or remedial action is required pursuant to law, regulation, order or govermmental action, provided that (i) no such removal or remedial action shall be taken except after reasonable advance written notice to the purchaser; (ii) any such removal or remedial action shall be undertaken in a manner so as to minimize any impact on the business conducted at the Property, and (iii) the vendor shall indemnify the purchaser for any action taken by the vendor under this section. The vendor shall at all times retain any and all liabilities arising from the handling, treatment, storage, transportation or disposal of environmental contaminants by the vendor or by any of the vendor's contractors in accordance herewith.

The vendor shall indemnify and save harmless the purchaser from and against any and all (i) liabilities, losses, claims, damages (including, without limitation, lost profits, consequential damages, interest penalties, fines and monetary sanctions), and costs (hereinafter "Loss"), and (ii) lawyers', on a solicitor and his own client basis, and accountants' fees and expenses, court costs and all other out-of-pocket expenses (the "Expense") incurred or suffered by the purchaser by reason of, resulting from, in connection with, or arising in any manner whatsoever out of the breach of any warranty or covenant or the inaccuracy of any representation of the vendor contained in this section. 
environmental statutes, for example, may impose liability on the vendor as a former owner. Also, third party contractual and tortious liabilities may extend the vendor's obligations in respect of the sold assets.

Where the purchaser has reason to be concerned about the vendor's ongoing financial viability, in addition to the standard indemnity it may also be prudent to require some form of security to ensure that the vendor will be financially able to fulfill its obligations (e.g., a holdback of part of the purchase price until cleanup is completed, escrow arrangements, letters of credit, performance bonds or third party guarantees). Naturally, from the vendor's perspective, limiting any such requirements is desirable.

Another issue which should be expressly addressed is the transferability of environmental warranties to successive purchasers. The seller will endeavor to have the agreement provide that the representations and warranties are personal to the parties, and that they provide no rights or remedies to third parties. The buyer, for its part, will seek the right to assign the warranties to subsequent buyers.

\section{LIABILITY ARISING FROM SUBSEQUENT USE}

Land which has been contaminated through use (e.g., sites of processing, refining or storage facilities) may continue to be suitable for the same use or may be suitable for other industrial purposes, but if used for different purposes (e.g., farming or recreation) the results may be disastrous.

When disposing of contaminated lands, a vendor can, with varying degrees of success, limit its potential liability to the purchaser by having the purchaser either covenant to use the lands for specific purposes only or acknowledge the existence of the contamination and correspondingly restricting the vendor's representations and warranties. Restrictions on use of the lands and other mechanisms for the limitation of the vendor's liability contained in the purchase and sale agreement will bind the parties to the agreement and, assuming they are adequately drafted, protect the vendor from liability arising from the purchaser's use of the land; however, difficulties are encountered in protecting against liabilities arising from subsequent purchasers' use of the land.

\section{A. LEASE}

In the case of severely contaminated land, the income derived from the sale may not offset the incremental increase in potential liabilities associated with the land. The owner may wish to, through retained ownership, control and restrict the use of the land and thereby reduce its potential liability. One method of continuing to assert control over the land, while having it generate income, is to lease rather than sell the lands. If this method is adopted, the lease should contain a lessee's acknowledgement of the contamination or prior use and a covenant of the lessee restricting its use of the lands.

\section{B. RIGHT OF FIRST REFUSAL}

If contaminated lands are to be sold, the concerned vendor may specify in the purchase and sale agreement the particular purpose or purposes for which the land 
is suitable. Any covenant relating to future use should be stated as applying to not only the purchaser but also its agents and affiliates. The vendor should also attempt to restrict the use of the land by subsequent purchasers. One method of retaining some control over the land may be to include in the sale agreement a covenant that the purchaser will disclose the contamination and restriction on use to any subsequent purchaser and to couple the covenant with a right of first refusal over the lands in favour of the original vendor.

Section 59.1 of the Law of Property $\mathrm{Act}^{83}$ makes a right of first refusal to acquire an interest an equitable interest and therefore caveatable under the Land Titles Act. A right of first refusal of unlimited duration would be prohibited by the rule against perpetuities but for section 18 of the Perpetuities Act. ${ }^{84}$ This section resolves the problem by permitting the interest subject to the right of first refusal to be acquired up to 80 years from the date of the contract which creates the right, but not thereafter. ${ }^{85}$

The right of first refusal should be registered by caveat and stated as applying to any proposed sale by the purchaser or any subsequent purchaser and the notice required on a proposed disposition should include mandatory delivery of a copy of the proposed purchase and sale agreement. By requiring delivery of a copy of the proposed purchase and sale agreement, the original vendor can monitor the original purchaser's compliance with its covenant to disclose the contamination to subsequent prospective purchasers. To ensure that the right of first refusal applies to subsequent purchasers, the original purchase and sale agreement should include a covenant by the purchaser to the effect that it will cause any subsequent purchaser to agree to be bound by the provisions in the original purchase and sale agreement relating to the right of first refusal.

\section{RESTRICTIVE COVENANT}

Theoretically, an alternative method of controlling the use of the contaminated land is to rely on restrictive covenants restricting the use of the land. The legal concept of restrictive covenants as interests in land was developed in the mid-nineteenth century to control the use and development of land. Given their history, restrictive covenants appear to be appropriate vehicles to ensure that lands are not used for purposes for which they are not fit. However, the law relating to restrictive covenants make their use generally impractical. In order that a restrictive covenant runs with the land:

(a) there must be a dominant tenement which benefits from the restriction to which the servient tenement is subject;

83. R.S.A. 1980 c. L-8.

84. R.S.A. 1980 c. P-4.

85. In Canadian Long Island Petroleums Ldd. and Sadim Oil \& Gas Co. Ltd. v. Inving Industries (Irving Wire Products Division) Lid. and Irving Industries (Foothills Steel Foundry Division) Ld., [1974] 6 W.W.R. 385 (S.C.C.), it was argued that a right of first refusal in respect of land created an interest in land and therefore offended the rule against perpetuities since the interest could vest at any time. The Supreme Court held that a right of first refusal did not create an interest in land and therefore, the rule against perpetuities was not offended. In response, the Legislature passed section 59.1 of the Law of Property Act which paradoxically, in constituting a right of first refusal an interest in land, resurrected the perpetuities problem. 
(b) the covenant must be restrictive or negative and must touch or concern the land (i.e. benefit or enhance the value of the dominant tenement); and

(c) the burden of the covenant must have been intended to run with the covenantor's land.

There are conceptual problems with the use by vendors of restrictive covenants to control subsequent uses of the land. In the usual case there would not be a dominant tenement benefited by the restrictive covenant. In some circumstances the vendor may hold two adjacent parcels of land and be selling only one, in which case the parcel the vendor retains may serve as the dominant tenement. In other cases, theoretically, a dominant tenement could be created by the sale of all but a small portion of the subject land; however, such a transaction would constitute a subdivision requiring approval pursuant to section 86 of the Planning Act ${ }^{86} \mathrm{In}$ any event, a plausible argument that the restrictive covenant is for the benefit of the dominant tenement is exceedingly difficult to construct. Therefore, an amendment to the Land Titles Act to provide for the possibility of owners registering caveats intended to disclose to future users of the lands the existence of contaminants should be considered.

At present, " it is the policy of the Land Titles Offices to examine such instruments [restrictive covenants] only for the requirements set forth in the Registration Procedure," which do not include assessment of whether the covenant is for the benefit of the dominant tenement. ${ }^{87}$ Given this policy, a vendor may consider the registration of an instrument which purports to be a restrictive covenant in the hopes that it may serve as actual notice to a subsequent purchaser.

\section{GIFT}

Another method of retaining control of contaminated lands may be to make a gift of them to a municipality or other local authority. The lands should be held in trust for the benefit of the municipality to be used for only the purposes specified in the instrument which constitutes the trust. While this plan does not generate income, it may provide a tax deduction.

\section{E. AGREEMENT WITH DEPARTMENT OF THE ENVIRONMENT}

Under section 7 of the Land Surface Conservation and Reclamation Act, for consideration, the Minister of the Environment may enter into an agreement on behalf of the Government with a landowner to restrict, indefinitely or for a specified term, the purposes to which that land may be used by that owner and its successors in title. The agreement itself may be presented for registration at the Land Titles Office, in which case the words "Agreement under Land Surface Conservation and Reclamation Act" will be endorsed on the certificate of title. If, as is the current practice of the Department of the Environment, a caveat in respect of the agreement is submitted, the certificate of title will be endorsed "Caveat Re: Reclamation Agreement by Minister of the Environment".

86. R.S.A. 1980 c. P-9.

87. Alberta Land Titles Procedure Manual, Volume 1, Procedure Number RES-1, date issued 1985-10-01. 
As of this date, this mechanism has been used in respect of municipally owned lands only. The most common use has been for lands previously operated by municipalities as sewage lagoons. At the time the municipalities ceased their operations of these sites there was no legislated obligation to properly reclaim them. The Department of the Environment has subsequently done the clean up (frequently using Heritage Trust Fund monies) and then registered, by caveat, agreements pursuant to section 7 of the Land Surface Conservation Reclamation Act. The agreements are registered so that, if the land is sold, the government can be reimbursed for its work out of the purchase monies. The Department of the Environment has also used these agreements in situations where they have reclaimed municipal land fill sites. In these cases, one of the express purposes of registration of these agreements is to identify, for subsequent users of the sites, the past usage of the site.

While this mechanism has not yet been employed with respect to private lands, when approached, the Department of the Environment expressed interest in this use of these agreements. Therefore, a vendor of land seeking to record notice of contamination associated with the land should consider the use of the mechanism provided by section 7 of the Land Surface Conservation Reclamation Act to disclose the contamination to future purchasers and users.

\section{INSURANCE COVERAGE FOR ENVIRONMENTAL DAMAGE}

\section{A. INTRODUCTION}

Since the period between an occurrence which results in environmental damage and the claim for such damage may be prolonged, in considering its insurance coverage, a company must consider not only policies currently available and the judicial interpretation of the provisions in respect of these policies, but also the policies it has procured in the past and the judicial interpretation of those provisions. While a discussion of the types and extent of insurance coverage available or advisable is well beyond the realm of most lawyers' expertise, a short discussion of the legal interpretation of insurance coverage in the context of environmental liability is warranted..$^{88.89}$

88. This portion of the paper draws heavily from "Issues in Insurance Coverage for Environmental Liabilities" by James T. Price in Environmental Considerations in Natural Resource and Real Property Transactions, The Rocky Mountain Mineral Law Foundation Mineral Law Series, Volume 1988, Number 4 which is recommended to the reader. While the article along with the case authorities cited in it are American, reliance on American material in the context of insurance law is common and accepted (Insurance Law in Canada, Brown and Menezes, Toronto 1982 at 22-23).

In his written dissent in Co-operative Fire \& Casualty Co. v. Saindon, 56 D.L.R. (3d) 556 at 559, Laskin C.J.C. considered American case law on interpretation of insurance policies and in doing so stated:

In accord with this view is a line of insurance cases in the American Courts dealing with exactly the situation that confronts us here. Cases in the United States on insurance matters have been freely cited in Canadian Courts because form policies developed in the United States have found their way into policies issued by insurers here: see 11 C.E.D. (Ont. 2nd) (1954), p.134, s.44 (Title, "Insurance"); 13 C.E.D. (Western 2nd) (1962), p.476, s.42 (Title, "Insurance"); and see, for example, Caldwell v. Stadacona Fire \& Life Ins. Co. (1883), 11 S.C.R. 212 at p.257; see also MacGillivray on Insurance Law, 5th ed. (1961), passim.

89. The discussion of judicial interpretation of insurance coverage is limited to the form known as Comprehensive General Liability and does not extend to industry-specific forms such as blowout insurance. 


\section{B. TYPES OF POLICIES}

Before 1966, Comprehensive General Liability ("CGL") insurance generally covered liability "caused by accident". In 1966, the standard-form CGL policy was revised so as to cover liability caused by an "occurrence". The occurrence type of policy contains a definition of occurrence which requires that the resultant damage be "neither expected nor intended" from the standpoint of the insured.

It has been suggested that for damages to be covered under the pre-1966 policies, the damages would have to have occurred contemporaneously with the causative event. The 1966 change to the definition of "occurrence" was intended to alleviate insureds' concerns that their policies did not extend to damage which was not contemporaneous with the causative event or which took place over time. In any event, judicial interpretation of the pre-1966 form made clear that it did so extend, thus the 1966 revision merely legitimized the judicial interpretation of the pre-1966 form.

In 1973, the standard-form CGL policy was further modified by expressly including in the definition of occurrence "continuous or repeated exposure to conditions" and the pollution exclusion clause was introduced.

Some relatively recent CGL policies utilize "claims-made" forms which provide the policy holder with protection against only claims made during the life of the policy. The standard-form policy in current usage contains the so-called "Total Pollution Exclusion", but a policy endorsement providing pollution coverage is available. In addition, many new CGL policies have undergone a change in name and are now called Commercial General Liability policies. These new restrictive claims-made policies are in part a reaction against the broad coverage extended insureds under occurrence type policies by virtue of judicial interpretation of same. The change of name is intended to avoid argument to the effect that "comprehensive" insurance raises the insured's reasonable expectations as to the extent of their coverage.

Limited Pollution Liability Insurance was introduced to the general public in 1985. It extends to pollution-related damage which is caused by an unexpected and unintentional discharge of pollutants from a structure or container provided that the discharge is noticed within 120 hours after the discharge has commenced and the quantity or quality of the discharge is not usual or routine to the insured's operation.

Environmental Impairment Liability is a comparatively new form of insurance which is not yet widely available. It is intended to cover damages caused by longterm or gradual pollution. Those insurers willing to provide this form of insurance emphasize risk assessment and active loss prevention programs. Risk assessment is usually conducted by environmental audit specialists and evaluated by the underwriter in order to determine: if the risk is acceptable, if specific terms and conditions (including specific exclusions) are warranted, and the amount of the premium. Underwriters may also make recommendations as to precautions to be taken or procedures to be followed by the insured in order to minimize the insurer's risk. 


\section{JUDICIAL INTERPRETATION OF POLICY PROVISIONS}

\section{Intentionality}

In cases involving environmental claims, insurers have argued that the damage is not covered because it was expected or intended, or the insured knew or ought to have known that its actions would result in damage to the environment. These types of arguments are most persuasive in circumstances where the pollutioncausing activity has continued over an extended period of time or where the insured has had notice that its actions were causing injury. In assessing such arguments, American courts have held that the proper test of intentionality is not whether the insured intended the act but rather whether it intended the consequential damage.

In considering foreseeability, Canadian courts also appear to focus upon the consequence of the act rather than the act. However, because many of the relevant cases involve deliberate courting of risk or reckless acts on the part of the insured, and because courts have found such deliberate acts to be intentional and excluded from coverage, the issue of whether it is the act or the consequence which must be unintended is frequently confused. Properly speaking, the Canadian test is double-barrelled:

(a) the consequence of the act must be unforeseeable; and

(b) the action which causes the injury must not constitute an intentional assumption of risk..$^{90}$

In considering the insured's intentions courts have not consistently applied a particular test. Most have applied the objective foreseeability test of tort law, but some have applied a subjective standard, and yet others have applied a hybrid test.

\section{Trigger of Coverage}

In cases involving delayed-manifestation damage claims, the most serious issue frequently concerns what triggers coverage. One author has suggested that there are four broad theories. ${ }^{91}$ The first is the "exposure trigger theory". Insurance

90. This double-barrelled test is adopted in the following quotations:

"Was the deceased's death an objectively foreseeable result of his actions and also did the deceased realize the danger of his actions and deliberately assume the risk of them?"

Johnson v. Mutual of Omaha Insurance Co. (1984), 8 D.L.R. (4th) 640 per Howland, C.J.O.

"Thus, in this case, we must consider not merely whether Colby's death was an objectively foreseeable result of his actions, but also whether he foresaw the possibility of his death and deliberately assumed the risk of it."

Excelsior Life Insurance Co. v. Colby (1980), 107 D.L.R. (3d) 333 at 343, per Lieberman, J.A.

91. The four theories are set out in James T. Price's article (see supra, note 62). In "Allocation of Liability for Latent Diseases Among Insurance Carriers" by Thomas R.M. Davis in Canadian Journal of Insurance Law (1986) Vol. 4, No. 1, pp 13-18 and "Pant II" in Canadian Joumal of Insurance Law (1986) Vol. 4, No. 2, pp 22-31, Davis states that Canadian theory relating to when coverage is triggered in cases conceming delayed manifestation of injury is undeveloped and in his discussion relies on American theory. His discussion parallels that of J.T. Price. 
coverage is triggered when an exposure causing damage takes place. ${ }^{92}$ Under the second theory, referred to as "manifestation trigger theory", coverage is triggered when an injury first manifests itself or becomes diagnosable irrespective of when the injury was sustained ${ }^{93}$ According to the third theory, called "injury-in-fact trigger theory", a policy covers any injury determined to have existed during the policy's term irrespective of exposure or manifestation. ${ }^{94}$ The final theory, called the "triple trigger" or "continuous exposure trigger theory", is the theory preferred by the insured. Coverage is triggered by any of the following three events:

(a) when an exposure which causes injury occurs;

(b) when the injury manifests itself; or

(c) when a latent injury develops or progresses. ${ }^{95}$

In considering the trigger of insurance in environmental damage cases, American courts have not consistently elected to apply one particular theory. Some courts have held that coverage is triggered when wastes or pollutants are disposed of or discharged. Other courts have held that the relevant time is when the contamination is first discovered. The triple trigger theory has been adopted in yet other cases. In such cases, the courts have recognized the continuous and progressive nature of such damage. Finally, several cases have applied the injury-in-fact test. If the evidence establishes damage occurred during a policy period, the policy is applicable whether the damage was manifest or not.

\section{Economic Loss}

In American cases involving costs claimed for environmental clean-up undertaken by a governmental regulatory agency who in turn demands payment from the policy holder, insurers have argued that such costs are not covered on the basis that they do not constitute "property damage". The costs do not arise out of damage to the insured's property but rather are "economic losses", which are excluded from coverage. American courts are divided on this issue of whether these costs are insured against. ${ }^{96}$

92. Examples of cases in which the exposure trigger theory was adopted are: Insurance Company of North America v. Forty-Eight Insulations, Inc., 633 F. 2d 1212 (1980) (6th Cir.), rehearing granted in part and denied in part, 657 F. 2 d 814 (1981), Cert. denied, 454 U.S. 1109; and Hancock Laboratories, Inc. v. Admiral Insurance Co., 777 F. 2d 520 (9th Cir. 1985).

93. The following are examples of cases which have applied the manifestation trigger theory: Eagle-Picher Insurance Inc. v. Liberty Mutual Insurance Company, 682 F. 2d 12 (1st Cir. 1982); and American Motorists Insurance Co. v. E.R. Squibb \& Sons Inc., 95 Misc. $2 \mathrm{~d} 222$ (N.Y. Sup. Ct. 1978).

94. Cases which have adopted the injury-in-fact theory include: American Home Products Corp. v. Liberty Mutual Ins. Co., 748 F. 2 d 760 (2d Cir. 1984) affirming 565 F. Supp. 1485 (S.D. n.4 1983); and Abex Corp. v. Maryland Casualty Co., 790 F. 2d 119 (D.C. Cir. 1986).

95. The leading case applying the triple trigger theory is Keene Corporation v. Insurance Company of North America, 667 F. 2d 1034 (D.C. Cir. 1981), Cert. denied, 455 U.S. 1007.

96. Examples of cases in which courts have rejected arguments that liability for costs claimed by govermment agencies for clean-up undertaken by them are excluded from coverage include: Chemical Applications Co. v. Home Indemnity Co., 425 F. Supp. 777 (D. Mass. 1977); and Kutsher's Country Club Corp. v. Lincoln Insurance Co. 465 N.Y.S. 2d 136 (N.Y. Sup. 1983). However, for an example of a case in which the contrary result was reached see: Port of Portland v. Water Quality Ins. Syndicate, 796 F. 2d 1188 (9th Cir. 1986). 
In Hildon Hotel (1963) Ltd. v. Dominion Insurance Corporation, ${ }^{97}$ the British Columbia Supreme Court held such costs were covered.

\section{Owned Property Exclusion}

The standard-form CGL policies contain an exclusion for property owned, occupied or controlled by the insured. In several American cases involving environmental clean-up of property owned or controlled by the insured, the courts have limited the application of this exclusion, holding that it did not apply to clean-up designed to protect either the groundwater underneath the insured's property (since that was not owned by the insured) or third parties' property.

Canadian courts have arrived at a similar result. In Hildon Hotel (1963) Ltd. v. Dominion Insurance Corporation, oil had leaked from a storage tank in the Hildon Hotel into the Vancouver harbour where it constituted a fire hazard to certain wharves and a danger to life. It was a source of potential pollution of beaches. The National Harbours Board rectified the problem and, after suing the hotel, obtained judgment for the cost of the clean-up. The court decided that the damage to the water system which was owned by the Crown in right of the province amounted to injury and as such was within the coverage of the policy. At page 294 the court stated: "The expense incurred by the harbours board in cleaning up the oil (and for which the judgment for damages was given) was incurred in mitigating and abating what constituted . . . a threat of continuing and further injury to the property of the wharf owners and others".

The case of Greenwood Forest Products Ltd. v. United States Fire Insurance Company ${ }^{98}$ also involved a leakage of chemicals from a lumber dip tank on property leased to the plaintiff company. The soil and ground water system was injured and had polluted the Fraser River and Skaha Lake. The plaintiff sought indemnity from the defendent insurer who denied liability under a policy containing a provision that the insured would be indemnified for damages or injury to property excluding damages to property leased to the insured. The Crown in right of Canada and the Crown in right of the province had obtained judgement against the insured. The issue was whether the occurrence involved damages because of injury to property, and whether the exclusionary clause in the policy, which stipulated that the policy did not apply to damage or destruction to property owned, used, occupied by or leased to the insured, applied. The court noted that the judgement awarded against Greenwood was for causing injury to the water system, the purity of which was the responsibility, by statute, of both governments. No property had been destroyed, but the water system was injured by the pollution. The court held that all of the costs necessarily incurred to retum the water to its pure state were recoverable under the policy, because all of them related to the injury and the treatment which was necessary to deal with the injury (at page 748). The court continued at page 748: "The policy provides that the insured will be indemnified for damages because of injury to property. Once it is decided that the costs were incurred to remove pollutants from the system then they are damages relating to the injury, i.e., incurred because of injury, and therefore fall within the policy".

97. 66 W.W.R. 289 (B.C.S.C.).

98. [1982] 3 W.W.R. 739 (B.C.S.C.). 
The court decided further that the need to drill holes on the leased property in order to render the water clean did not amount to damage to the leased property which was being repaired, but to injury to the entire water system which was being treated. In the result, the insured was entitled to indemnification for the entire amount of the judgement in favour of the Crown.

\section{The Pollution Exclusion}

In the United States, the original forms of pollution exclusion clauses were frequently construed as merely restating the general proposition that the insurer is not liable for pollution-related damage which is expected or intended from the standpoint of the insured. Under the new so-called Total Pollution Exclusion, even pollution-related damage which is sudden and accidental is not covered. To be insured against such loss, one must purchase a separate policy for "Sudden and Accidental Pollution" or the more costly "Environmental Impairment Liability" policy, which extends if required to both gradual pollution and sudden and accidental pollution.

When the policy at issue contains a pollution exclusion clause, it is usual that the insurers will attempt to rely on this clause in environmental damage cases. Since ambiguities in exculpatory clauses are strictly construed against the party relying on the exclusion, policy holders have frequently argued against the application of the exclusion clause on the grounds that it is ambiguous. Such arguments have on occasion been accepted by American courts.

The ambiguity arises because the policy is stated generally as covering occurrences which, by the definition given in the policy, extend to conditions continuing in nature, while the exclusionary clause precludes coverage unless the pollution is sudden. Insurers have successfully relied on the pollution exclusion clause in cases where they have established that the discharge was not sudden and accidental. Examples involve cases in which there had been continuous or repeated discharges over extended periods of time.

Pollution exclusion clauses have also been the subject of litigation in Canada. In Zatko v. Paterson Spring Service Limited, ${ }^{99}$ the plaintiffs owned land downhill from the defendant's property. A leak from an underground oil tank located on the defendant's property damaged the plaintiffs' lands. The defendant and its insurer had negotiated a settlement with the plaintiff, but the damage recurred and the plaintiff sued the defendant for the subsequently incurred damages. The defendant brought a third party claim against its insurer claiming indemnity. The issue in the third party claim was whether the escape was "sudden and accidental"; if so, the injury would fall outside the pollution exclusion clause and the insurance company would be bound to indemnify the defendant. In this case, the fact that the leak was gradual and extended over a prolonged period of time and that the insured had had knowledge of the prior problem were fatal to its claim. In obiter, the court stated that the injury caused by the initial escape (that is, the injury in respect of which the settlement agreement was executed) constituted an injurable loss.

In reaching its decision the court cited with approval Park Plaza Cleaners Ltd. v. Saskatchewan Government Insurance. ${ }^{100}$ This case involved a defective boiler,

99. (1986), C.I.L.R. [1-1997] (Ont. S.C.).

100. (1983), C.I.L.R. [1-1598]. 
and an insurance policy similar to that discussed in Zatko. The judge's determination was that, "[in] my view, this was an ongoing problem and therefore the loss of February 2, 1980, was not, in my opinion, a sudden and accidental breakdown. The plaintiff in view of the history of the boiler, which the plaintiff well knew, should have been able to anticipate the problem".

The pollution exclusion clause was also considered in Grace Farms Limited v. Big A Tank Services $L t d{ }^{101}$ In that case the plaintiff, a pig farmer, had collected a large quantity of pig manure in a holding tank. The defendant, an expert in disposing of pig manure, negligently disposed of it in such a way that it ran into the Fraser River. The plaintiff claimed against the defendant for the cost which he had been compelled to pay to clean up the stream and the defendant joined his general liability insurers. The court held that the phrase "waste materials or other irritants, contaminants or pollutants" should not be interpreted to include manure. As the judge stated, "To hold that property damage arising out of the discharge of the manure on to the land or into any water or water course is excluded from coverage unless same is sudden and accidental, would be to hold the defendant purchased no coverage for what was the pervasive and obvious risk in its business" (at page 144).

\section{Duty to Defend}

Under standard-form CGL policies, the insurer has a duty to defend and indemnify the insured against any suits relating to damages for bodily injury or property damage. Since it can be extremely expensive to defend against claims arising out of environmental related accidents, the right to a defence is important. American courts have held that the duty to defend is broader than the duty to indemnify. Insurers have been held liable to defend claims "potentially or arguably within the policy's coverage". ${ }^{102}$

\section{Timely Notice}

To preserve rights accorded the insured under an insurance policy, it is crucial that timely notice be given the insurer in accordance with the policy terms. In determining which insurers to notify in cases of environmental contamination, the insured should consider as potentially relevant dates all periods from the initial cause through the progression and culmination of the damage, and notify each of its insurers in each of those periods. While some American courts have held that notice to the insurer's broker constitutes notice to the insurer, the preferred practice is written notice directly to the insurance company.

In cases involving claims-made policies, the issue of notice is often related to the issue of what constitutes a claim; an insured is obligated to report claims made against them in a timely manner, however, determination of at what stage a complaint against an insured constitutes a claim made against it is difficult to determine. ${ }^{103}$

101. (1984), 6 C.C.L.I. 136 (B.C.S.C.).

102. Russell Stover Candies, 649 F. 2d at 624, citing, Hartford Accident \& Indemnity Co. v. Kreklen, 491 F. 2d 884, 886-887 (8th Cir. 1974).

103. For a discussion of this issue the reader is referred to " 'Claims Made' Commercial General Liability Policy - A Discussion of Some Important Aspects" by Neil C. Wittmann, Q.C., in Insight, Insurance Seminar, May 15, 1986, Calgary. 


\section{ENVIRONMENTAL ISSUES OF CONCERN TO LENDERS}

\section{A. INTRODUCTION}

Lenders taking security on oil and gas assets may inadvertently assume environmental liabilities relating to the assets over which they have security, particularly upon realization of their security.

Until recently, there were essentially two sources of the lenders' abiding concern and interest in the borrower's assets and operations: Firstly, the possibility that some problem associated with the assets or operations may impair the borrower's ability to repay the loan, and secondly, the possibility that in the event of realization, a problem with the assets or operations may impair the realizable value of the lender's security.

Recently, lenders have acquired a new reason for concern about the borrower's assets and operations. Today, a lender or alternatively its receiver must worry about its potential liability in respect of the lender's operation and assets.

The following discussion begins with issues which are associated with realization, then deals with concerns relating to lender liability which are not specific to realization, and concludes with some recommendations to lenders. ${ }^{104}$

\section{B. LENDERS' CONCERNS ON REALIZATION}

Upon realization, the lender has three areas of concern arising from environmental problems associated with the borrower's assets or operations:

(a) existing environmental problems may reduce the price received for the borrower's assets;

(b) ongoing obligations to remedy environmental problems may decrease the revenues received by the lender from the borrower's assets; and

(c) the lender may assume liability for environmental problems associated with the borrower's assets.

\section{Reduction in Value}

Serious environmental problems associated with the lender's assets will reduce the realizable value of the assets and it is this possibility that makes the lender's situation analogous to that of a purchaser.

Since lenders are in a position analogous to that of a purchaser, they should seek protections in loan agreements similar to those which purchasers obtain in purchase and sale agreements. Specifically, an agreement providing for a loan secured against oil and gas assets should contain representations and warranties as to past operations and conditions of assets similar to those contained in a purchase and sale agreement, and the covenants in the loan agreement as to future operations should be patterned after those in respect of interim operations contained in a purchase and sale agreement.

104. A thorough treatment of lender liability for environmental impaiment is beyond the scope of this paper. For a more thorough treatment, the reader is referred to "Environmental Liability: The Growing Risks for Lenders, Receivers and Trustees" by Geoffrey Thompson in Avoiding Environmental Liability in Real Estate \& Business Transactions, The Canadian Institute, Spring 1989, which was relied upon in the preparation of this segment of this paper. 
Additionally, the lender's due diligence process should parallel that of the purchaser. It should include public searches, specific inquiries relating to compliance with environmental protection legislation and potential environment-related liabilities, and, where warranted, environmental audits.

\section{Cost of Ongoing Obligations}

Receivership or bankruptcy may not provide a mechanism for avoiding statutory obligations to comply with environmental legislation applicable to the borrower's operations and the necessity of compliance may seriously erode the amount received on realization.

The Ontario case of Canada Trust Company v. Bulora Corporation Limited ${ }^{105}$ addresses this issue. Bulora operated a gold mine and owned a neighbouring townsite for mine employees. The mine was shut down and some of the abandoned houses became fire hazards. The Fire Marshall served a repair/demolition order on the receiver of Bulora.

The receiver argued that the receivership had not extinguished the legal existence of Bulora and therefore Bulora was the "person", within the meaning of the Fire Marshall's Act, on whom the obligation to comply with the order should rest. The trial judge held that as the receiver was granted very wide powers to manage the business of Bulora, it was appropriate for the Fire Marshall to "serve the receiver on behalf of Bulora". The trial judge then went on, at page 152, to address the question of who should bear the cost of the demolition as follows:

There remains the major problem of determining who should bear the costs of the demolition. The order of the Fire Marshall is of vital concern for the safety of residents of the units adjacent to and close by the abandoned units. The safety of those persons occupying such units should be of paramount importance. If the receiver is given wide and sweeping powers in the management of the company, surely in the course of such management it has a duty to comply with a demolition order where the safety of individuals is so vitally concemed. It is indeed unfortunate that a creditor must suffer the loss resulting from the demolition. Nevertheless, the asset to be managed by the receiver must, in my opinion, be managed with a view to the safety of those residing in and beside that asset. Receivership cannot and should not be guided solely by the recovery of assets. In my view, there is a social duty to comply with an onder such as this which deals with the safety of individuals affected by an asset the receiver is managing.

The judge then directed the receiver to comply with the order.

The Court of Appeal ${ }^{106}$ upheld the trial judge's decision, but rejected any concept of the receiver's "social duty", saying that the duty involved was a statutory one and there was no necessity to consider the social implications of the order.

In Alberta, many of the applicable statutes which impose duties on "persons", "operators" and "owners" define those terms so widely that a receiver could easily be caught. For example, under the Land Surface Conservation and Reclamation $A c t$, when the Council is authorized to make a reclamation order, the order may direct the performance of any work that is necessary to condition, maintain or reclaim land. A reclamation order must be directed to the operator concerned. An operator is defined in section 34 as:

"(i) a person in whose favour a surface lease ... is held . . . or the agent of that person,

.... or

105. (1980), 34 C.B.R. (N.S.) 145 (Ont. H.C.).

106. (1981), 39 C.B.R. (N.S.) 152 (Ont. C.A.). 
(iv) a person who, whether as principal or agent and whether as owner or not, uses or has used [the] land ..."

As many receivers are given wide powers of management and control, they may be considered to be operators of lands. Following the reasoning in the Bulora case, the liability for reclamation may fall on the receiver.

\section{Lender Liability}

The lender may attract liability either in a realization scenario, as a consequence of its ownership or control over the assets, or by virtue of its participation in the business of the borrower. The degree of lender's potential liability upon realization will depend, to a certain extent, upon the method of realization selected: private appointment of receiver, court-appointed receiver, appointment of an agent pursuant to section 177 Bank Act security or trustee in bankruptcy.

With respect to a privately-appointed receiver, generally under loan documentation, it is agreed by the parties that a receiver appointed by the lender shall be the agent of the borrower. Consequently, tortious or statutory liability arising from environmental damage caused by the privately-appointed receiver should not be attributed to the lender. However, courts are not always willing to recognize the receiver as agent of the company. In Peat Marwick Ltd. v. Consumers Gas Co. ${ }^{107}$ it was stated: (at page 344)

It seems to me that [the receiver] in a situation like the present is wearing two hats. When wearing one hat, he is the agent of the debtor company; when wearing the other, the agent of the debenture holder. In occupying the premises of the debtor and in carrying on the business, the receiver and manager acts as agent of the debtor company. In realizing the security of the debenture holder, notwithstanding the language of the debenture, he acts as agent of the debenture holder, and thus is able to confer title on a purchase free of encumbrance.

Should the court refuse to recognize the receiver as agent of the company, the lender may be liable as principal of the receiver. Additionally, if, as is typically the case, the lender has agreed to indemnify the receiver against losses incurred by it as a consequence of its actions as receiver, the lender may by virtue of the indemnification be liable for injury caused by the receiver.

In contemplating the potential for receiver liability, it should be noted that receivers do not become the owners of the borrower's assets, accordingly, they should not be personally responsible for any liabilities that are contingent upon ownership. ${ }^{108}$ However, certain types of liability may not depend upon ownership but rather control, and it is liabilities falling into this latter category which may be attributed to receivers. For example, if a receiver negligently conducts operations so that a contaminant escapes from the borrower's property and damages an adjacent property, the receiver may be liable in negligence to the adjacent landowner.

In the case of a court-appointed receiver, the receiver is not acting as agent of the company or the secured creditor, but rather as agent of the court. The court

107. (1981), 29 O.R. (2d) 366 (Ont. C.A.).

108. Prior to December 16,1981 , only security taken by chartered banks pursuant to the Bank Act was registrable under the Mines and Minerals Act, consequently, loans made by non-chartered banks were occasionally structured such that title to the borrower's assets was transferred to a nominee of the lender. Some of these loans continue in their original form today. In these situations, the nominee is at least nominally the owner of the assets and as such, must be concerned about statutory environmental liabilities imposed on owners. 
appointment does not immunize the receiver against all liability, as a courtappointed receiver may be sued with the leave of the court. If the court-appointed receiver is personally liable for damages caused by it in the course of its administration, the lender may only be liable for the damages claimed against the receiver under any indemnification given the receiver by the lender.

With respect to a trustee in bankruptcy, the trustee takes title to and possession of the bankrupt's assets. Since the trustee takes both title to and control of the borrower's assets, the possibility of it incurring liability is greater than the receiver. The receiver need only worry about liability which attaches by virtue of control, whereas the trustee must also concern itself about liability arising by virtue of its (nominal) ownership. This issue has arisen in the context of American cases involving prosecutions under CERCLA of owners for recovery of the costs of emergency clean-up conducted by the government. To date, the courts have displayed a reticence to find nominal owners liable. ${ }^{109}$

Like the court-appointed receiver, the trustee may only be sued with the leave of the court. Generally, a trustee is indemnified out of the bankrupt's estate for liabilities incurred in the course of performance of his duties. In the case of the trustee, the lender is not liable for the damages caused by the trustee, however, the amount it receives at the end of the realization process will be diminished by amounts paid out of the bankrupt's estate by virtue of the indemnification of the trustee. Of course, if the lender has indemnified the trustee, then it may be liable under its indemnification.

The position of an agent appointed pursuant to Section 177 Bank Act security is unclear. The prevailing view is that its position is akin to that of a mortgagee-

109. Under CERCLA, the government is entitled to recover clean up costs from an "owner or operator" of a hazardous waste site, however, the Act provides that:

"Such term [owner or operator] does not include a person who, without participating in the management of a vessel or facility, holds indicia of ownership primarily to protect his security interest in the vessel or facility."

It is by virtue of the above exclusion that most nominal owners have escaped liability. In cases where ownership or control exceeded what was necessary to preserve their security, lenders have been held liable.

In United States v. Mirabile 15 Env. L. Reptr. 20994 (E. Del. 1985), the court considered the security interest exemption and whether it shielded various mortgagees from liability as owners. In doing so, the court stated at page 20996:

. . . that before a secured creditor such as [American Bank] may be held liable, it must, at a minimum, participate in the day-to-day operational aspects of the Site. In the instant case, [American Bank] merely foreclosed on the property after all operations had ceased and thereafter took prudent and routine steps to secure the property against further depreciation.

In United States v. Maryland Bank \& Trust Co. 16 Env. L. Reptr. 20559 a bank which foreclosed on a hazardous waste site was liable for the government incurred clean-up costs. In its reasons for its decision, the court stated at page 20559:

The [Bank] purchased the property at the foreclosure sale not to protect its security interest, but to protect its investment. Only during the life of the mortgage did [the Bank] hold indicia of ownership primarily to protect its security interest in the land. Under the law of Maryland (and 12 other states), the mortgagee-financial institution actually holds title to the property while the mortgage is in force. Congress intended [by the security-interest exception] to exclude these common-law title mongagees from the definition of 'owner' since title was in their hands only by operation of the common-law. The exclusion does not apply to former mortgagees currently holding title after purchasing the property at a foreclosure sale, at least when, as here, the former mortgagee has held title for nearly four years . . . 
in-possession and, as such, the agent may be liable for damages caused during its occupation and for breaches of statutory obligations where liability is based on occupation or possession. Since the agent's rights include many of those which are generally indicia of ownership under any statutes which contain broad definitions of owners, the agent may be liable for breaches of the statutory obligations imposed on owners.

In the case of agents under Section 177 Bank Act security, there is a strong case for finding the lender liable as principal for the agent, therefore, the lender may incur liability by virtue of either its role as principal or the indemnification it provided its agent.

\section{LIABILITY ON ASSUMPTION OF CONTROL}

The trend in recent environmental legislation is toward the imposition of personal liability and responsibility on all persons who exert control and direction over operations associated with environmental impairment. This trend is a likely source of lender liability for environmental damage caused by the borrower's operations.

This liability may attach both prior to and in the course of realization. In the context of participation loans, for example, lenders have always been cognizant that they may at law be found to be in partnership with their borrowers, and, accordingly, have typically structured transactions so that they do not inadvertently constitute a partnership. However, short of partnership, lenders have not been concerned about liability arising from the degree of control exercised by them over the borrower's business. Especially in the case of loans to financially distressed companies, lenders have frequently actively participated in the management of their borrower's affairs: directly, by the appointment of directors and officers, and indirectly, by requiring that business decisions and plans receive their prior approval. Currently, the possibility of incurring liability by virtue of holding a directorship is being taken seriously, but there is not yet the same awareness with respect to indirect forms of control.

Additionally, lenders should be appraised of the risks associated with controlling Administrators. Under the new generation of environmental statutes, not only the Administrator as agent of the borrower or court may be liable for environmental damage but also any person who controls the Administrator.

\section{RECOMMENDATIONS TO LENDERS}

The lender's due diligence process should include the same kinds of assessments of environmental risks as are employed by purchasers including where appropriate environmental audits. Also, loan documentation should include the same kinds of representations, warranties and covenants as recommended to purchasers. In addition, under the loan agreement the lender should be indemnified for any loss resulting from it or its agents liability for environmental clean up or damages.

Through every aspect of its relationship with the borrower, the lender should be aware of the degree of its control over and participation in the borrower's operations, and concern itself as to the potential liability such behaviour attracts. It is generally only in circumstances where the lender has interfered with control of the business or when it or its agents have become owners of the lender's assets (as a 
consequence of realization), that it will expose itself to liability for environmental damage. In the event that a lender determines to realize on its security, in selecting a method of proceeding it should consider the extent of its exposure to liability for environmental damage. It is usually better not to become an owner of the property nor to have the assets controlled or owned by its agents.

Lastly, in any instrument pursuant to which it appoints an Administrator, there should be covenants by the Administrator to comply with environmental legislation. The lender may also consider excluding from its indemnification of Administrators environmental damages at least when such are occasioned by the Administrator's negligence or failure to comply with either industry standards relating to environmental protections or legislation.

\section{CONCLUSION}

In Alberta, drafters of oil and gas agreements are with increasing frequency dealing creatively with environmental law issues. This trend can be expected to accelerate as environmental issues continue to attract public interest, particularly if Alberta follows the lead of other jurisdictions in enacting more enforcement-oriented environmental protection legislation. Reinforcing the trend is the increased drilling and production in environmentally-sensitive areas and the increasing reclamation obligations as fields deplete.

For these reasons, drafters of oil and gas agreements must continue to increase their knowledge of environmental issues and legislation and seek further innovative ways of using their knowledge in drafting agreements so as to protect their clients' interest.

\section{APPENDIX "A"}

\section{LIST OF KEY LEGISLATION WITH ENVIRONMENTAL IMPLICATIONS}

\section{FEDERAL LEGISLATION}

Arctic Waters Pollution Prevention Act,

R.S.C. 1970 , c. 2 (1st Supp.)

Arctic Shipping Pollution Prevention Regulations

Arctic Waters Pollution Prevention Regulations

Atomic Energy Control Act,

R.S.C. 1970 , c. A-19

Transport Packaging of Radioactive Materials Regulations

Uranium and Thorium Mining Regulation

Canada Shipping Act,

R.S.C. 1970 , c. S-9

Air Pollution Regulations

Garbage Pollution Prevention Regulations

Oil Pollution Prevention Regulations

Pollutant Substances Regulations

Canada Wildlife Act,

S.C. $1973-74$, c. 21

Wildlife Area Regulations 
Canadian Environmental Protection Act,

S.C. 1988 , c. 22

Regulations formerly under Environmental Contaminants Act

Regulations formerly under Clean Air Act

National Emission Standards

National Emission Guidelines

Regulations formerly under Canada Water Act

Criminal Code,

R.S.C. 1970 , c. C-34

Fisheries Act,

R.S.C. 1970 , c. F-14

Liquid Effluent Regulations

Liquid Effluent Guidelines

National Energy Board,

R.S.C. 1970 , c. N-6

Gas Pipeline Regulations

National Parks Act,

R.S.C. 1970 , c. N-13, Act to Amend, S.C. 1974, c.11

Lease \& License of Occupation

Navigable Waters Protection Act,

R.S.C. 1970 , c. N-19

Navigable Waters Works Regulations

Oil and Gas Production and Conservation Act,

R.S.C. 1970 , c. $0-4$

Oil and Gas Spills and Debris Liability Regulations

Pest Control Products Act,

R.S.C. 1970 , c. P-10

Pest Control Products Regulations

Guidelines for Registering Pesticides and other Control Products under the Pest

Act in Canada

Control Products

Transportation of Dangerous Goods Act,

S.C. $1980-81-82-83$, c. 36

Transportation of Dangerous Goods Regulations

\section{PROVINCIAL LEGISLATION}

Agricultural Chemicals Act,

R.S.A. 1980 , c. A-6

Pesticide Applicator Licensing Regulation

Pesticides Sales, Use and Handling Regulation

Clean Air Act,

R.S.A. 1980 , c. C-12

Regulations:

AR 33/73 Clean Air Regulations

AR 216/75 Clean Air (General) Regulations

AR 218/75 Clean Air (Maximum Levels) Regulations

Natural Gas Processing Plant Regulation

Guidelines for:

Stack Exit Temperatures for Acid Gas

Incinerators Associated with Gas

Processing Plants

Guidelines for:

Sulphur Recovery and Sulphur Dioxide

Emissions at Gas Processing Plants 
Clean Water Act,

R.S.A. 1980 , c. C-13

Regulations:

AR 35/73 Clean Water (General) Regulation

AR 36/73 Clean Water (Industrial Plants) Regulation

Guidelines for:

Clean Water (Authority Designation Municipal Plants)

Guidelines for:

Waste Water Effluent Guidelines for Alberta Petroleum Refineries

Gas Processing Plants-Waste Water Management Standards

Coal Conservation Act,

R.S.A. 1980 , c. C-14

Coal Conservation Regulations

Coal Development Policy

Department of Energy Act,

S.A. 1986 , c. D-18.1

Department of the Environment Act,

R.S.A. 1980 , c. D-19

List of Restricted Development Areas

Department of Forestry, Lands and Wildlife Act,

S.A. 1986 , c. D-20.5

Energy Resources Conservation Act,

R.S.A. 1980, c. E-11

Rules of Practice

Environment Council Act,

R.S.A. 1980, c. E-13

Fire Prevention Act,

S.A. 1982, c. F-10.1

Fire Code

Lightning Rod Sale, Installation \& Maintenance

Forest and Prairie Protection Act,

R.S.A. 1980 , c. F-14

AR 135/72 The Forest \& Prairie Protection Regulations (Part I)

AR 310/72 The Forest \& Prairie Protection Regulations (Part II)

Forests Act,

R.S.A. 1980 , c. F-16

Exploration

Forest Land Use \& Management

Timber Management Regulations

Gas Resources Preservation Act,

S.A. 1984, c. G-3.1

Ground Water Control Act,

R.S.A. 1980, c. G-11

Ground Water Development Act,

R.S.A. 1980, c. G-11.1

Water Well Drilling \& Construction

Hazardous Chemicals Act,

R.S.A. 1980 , c. H-3

Hazardous Waste Regulations

Historical Resources Act,

R.S.A. 1980 , c. $11-8$

Hydro and Electric Energy Act,

R.S.A. 1980 , c. H-13

Hydro \& Electric Energy Regulations 
Land Surface Conservation and Reclamation Act,

R.S.A. 1980, c. L-3

AR 125/74 Land Conservation Regulations

AR 207/76 Regulated Oil and Gas Pipeline Surface Operations

AR 159/76 Regulated Oil Sands Surface Operations

AR 172/77 Security Deposit Ministerial Regulations

Environmental Impact Assessment System Guideline

Litter Act,

R.S.A. 1980, c. L-19

Litter Control Regulations

Mines and Minerals Act,

R.S.A. 1980, c. M-15

AR 423/78 Exploration Regulation

Crown Petroleum Production

Development Drilling Incentive

Petroleum \& Natural Gas Agreements

Municipal Government Act,

R.S.A. 1980 , c. M-26

Oil \& Gas Well Drilling

Oil and Gas Conservation Act,

R.S.A. 1980, c. 0-5

AR 151/71 Oil and Gas Conservation Regulations

Oil Sands Conservation Act,

S.A. 1983 , c. $0-5.5$

Release of Information Regulation

Pipeline Act,

R.S.A. 1980, c. P-8

AR 122/87 Pipeline Regulation

Planning ACt,

R.S.A. 1980, c. P-9, as amended

Alberta Planning Board Jurisdiction

Regional Planning Commissions Subdivision

Public Health Act,

S.A. 1984, c. P-27.1

Waste Management Regulation

Public Lands Act,

R.S.A. 1980 , c. P-30, as amended

AR 423/78 Exploration Regulation

Mineral Surface Leases

Pipeline Permits

Soil Conservation Act,

R.S.A. 1980, c. S-19

Special Waste Management Corporation Act,

S.A. 1982, c. S-21.5

Surface Rights Act,

S.A. 1983, c. S-27.1

Rules of Practice \& Procedure

Transportation of Dangerous Goods Control Act,

S.A. 1982, c. T-6.5

Transportation of Dangerous Goods Control Regulation

Administration Regulation

Turner Valley Unit Operations Act,

R.S.A. 1980 , c. T-12

Water Resources Act,

R.S.A. 1980, c. W-5, as amended

AR 91/58 Water Resources Regulations

Provincial Water Power Regulation 
Wildlife Act,

S.A. 1984, c. W-9.1, as amended

General Wildlife

Wilderness Areas, Ecological Reserves and Natural Areas Act,

R.S.A. 1980, c. W-8

Ecological Reserves

Natural Areas Designation

\section{OTHER}

Municipal By-Laws 